\title{
Capítulo 4 \\ La ontología de Rodolfo Kusch. Una apuesta filosófica desde contextos culturales propios del pensamiento indígena y popular
}

E la investigación sobre la ontología de Kusch hemos avanzado,
hasta ahora, en dos frentes: con el primero se buscó comprender el concepto de ontología, y así tener un marco teórico general para la indagación, y en el segundo se rastrearon los aportes de Rodolfo Kusch al proyecto de su ontología. Ambos, como se ha visto, han sido fruto de un riguroso ejercicio de hermenéutica textual, gracias al cual se pudo comprender el sentido de la obra filosófica de los pensadores abordados: su interés investigativo, sus conceptos fundamentales y sus apuestas ontológicas.

En el primer capítulo se aclaró, a la luz de Heidegger, el concepto de ontología en la historia de la filosofía, incluyendo la apuesta personal del filósofo alemán, que nos sirve como marco teórico y contextualiza la obra filosófica de Kusch. En el tercer capítulo se avanzó hacia la comprensión de los lineamientos ontológicos que desarrolla en sus textos el pensador argentino. ¿Qué nos resta ahora? ¿No quedó señalada ya, de alguna manera, la apuesta ontológica de Kusch? $¿$ No parece evidente el influjo que sobre Kusch ejercieron los aportes de Martin Heidegger? Es muy posible que así sea, pues parece que ya se ha logrado un nivel de claridad y de evidencia. Sin embargo, no hay duda de que también falta dar respuesta a las preguntas: ¿en definitiva, 
cuál es la ontología de Kusch?, ¿cuál es la estructura fundamental desde la cual se sostiene la apuesta filosófica de este pensador latinoamericano?, ¿en qué medida se podría enunciar que la ontología de Kusch es una apuesta propia de la filosofía latinoamericana?

Pues bien, tras la búsqueda de respuesta a estos interrogantes se avanzará en esta parte de la investigación. En primera medida, se retomará, en síntesis, lo ya ganado y avanzado para contextualizarnos; luego se fijarán los conceptos fundamentales de la filosofía kuschiana, y, por último, a manera de conclusión, se señalará la dinámica propia de la ontología de Kusch, sus límites y posibilidades.

\section{La ontología, Heidegger y Kusch}

Resulta evidente que el concepto de ontología que guía esta investigación se configura en el devenir histórico que la filosofía, ha construido gracias a los pensadores que se han preguntado por el problema del ser en cuanto ser. En el siglo xx, sobresale Heidegger por el hecho de haber dedicado toda su vida a la búsqueda de sentido del ser, en un diálogo constante, profundo y renovado con los grandes filósofos que le antecedieron. Aquel diálogo nos ha abierto un horizonte para introducirnos en este problema, siempre vigente, como él mismo dijo, problema "de antes, de ahora y de siempre", jamás resuelto, y de nuevo traído a discusión en una y otra época, desde uno y otro contexto.

Ya la sentencia filosófica más antigua, que es un fragmento de Anaximandro, pone delante, según Heidegger, la comprensión de las cosas como ente. De alguna manera patentiza la diferencia con el ser, distinción que se va olvidando y va dando paso al olvido del ser, desde los mismos comienzos de la filosofía griega. Aquel ente, según Heráclito, no se encierra en sí mismo ni ahí-ante-los-ojos, pues al ponerse delante se devela en un continuo devenir que los seres humanos percibimos como presencia (lo-que-es, presencia del ser), pero que, al nombrarlo, el lenguaje lo acoge, lo cuida, lo guarda y se hace su morada, de donde se infiere que este, el lenguaje, es la morada del ser.

En Parménides el ser es, es lo único que es, es lo único presente siendo en el tiempo. Si se trata de apañarlo desde alguna de sus 
particularidades no tendremos más que una opinión, por ello hay que buscar comprenderlo en su totalidad. No se piensa el ente (él está ahí, como ente) ni se piensa el ser como tal, pues lo pensable es una especie de pliegue que del ente va al ser o que evidencia al ser desde el ente: este, en ese develar su ser y mostrar delante (hacer presencia) el ser en cuanto tal, en ese pliegue entre ente y ser se identifican pensar y ser, pues eso es justo lo que se piensa: el ser que se des-pliega en el ente. ¿Y qué es este "pliegue"? Nada más que la verdad. La verdad es lo pensado del ente como ser: acaece la verdad como ser del ente.

A propósito del mito de la caverna de Platón, Heidegger señaló cómo de camino al ente, a las cosas mismas, nos topamos con su ser. El ser de lo ente es lo que apañan las ideas. Estas no son entes, de ninguna manera, lo que ellas transparentan es el ser: ante el ente, el ser se vislumbra como idea. El ente está en sí, como cosa, como objeto; la idea nunca es objeto. Pero esto tampoco quiere decir que sea sujeto. La idea es lo que verdadea el ente. En el Teeteto, se nos hace ver que nuestra primera experiencia con el ente es la percepción; lo percibido es lo que es. Luego, en la segunda experiencia, nos detenemos en los detalles, en las determinaciones de lo percibido, caracterizando lo que es y lo que no es, para determinarlo. Por último, dicha determinación solo es alcanzada por una comprensión ontológica previa de quien percibe, a la que Heidegger llama aspiración al ser.

De lo anterior se concluye que la experiencia ganada con la percepción es ontológica. El ser es lo aspirado en la existencia del ser humano: todo su sentido se abre bajo el horizonte de dicha aspiración. El ser es una experiencia existencial, y existencialmente ontológica. Sin esta posibilidad existencialmente ontológica, el ser humano jamás podría habérselas con el ente. Pero al habérselas con el ente, lo primero que acaece es la percepción, y en el acto de percibir opinamos. La opinión es, entonces, la primera aproximación al sentido del ser, pues gracias a ella se alcanza una apariencia (aproximada) del ser, lo que en griego no significa algo despectivo, sino la constatación que se da entre la visión y lo visto, entre el ente y su aparecer (apariencia) ante la visión (de quien aspira al ser).

La opinión acaece justo en este pliegue entre visión y visto, entre verdad y apariencia, entre ser y no ser, pliegue que tal vez sea lo único 
que podamos conocer, pues al ente en sí jamás hemos tenido acceso y el ser en cuanto tal siempre se nos ha escurrido. Al parecer, estamos tan próximos como tan lejanos del ser, la verdad se nos aproxima tanto como se evapora y se nos pierde. No ser y no verdad se nos ofrecen en su apariencia tanto como ser y verdad, y así deviene el juego de la apariencia que se refleja en la opinión. Aunque Heidegger no lo sentencie de manera explícita, pareciera que quisiera decirnos que al final, en el fondo de todos nuestros estudios e investigaciones, no queda más que mera opinión, entendida esta como aproximación al ser desde la apariencia del ente.

El primer encuentro de Heidegger con Aristóteles, por no decir que con la filosofía, fue en 1907 al leer De los diferentes modos del ente en Aristóteles, escrito por Brentano. Quince años después, Heidegger presentó el Informe Natorp, donde analizó que la comprensión del ser en Aristóteles ya evidencia el concepto de la verdad como develamiento, como desocultamiento, sentido que está incluido en la apuesta de potencia y acto como forma de acaecimiento del ser, sobre "la base" de su comprensión fundamental como ovor ("hacienda, lo que se tiene a mano para poder vivir, lo sustancial').

También hay que decir que es a la luz de Aristóteles que Heidegger va comprendiendo y asumiendo la diferencia ontológica entre ser y ente, en particular con su curso de 1926, publicado como Conceptos fundamentales de filosofía antigua (2014a). Según dicho curso, Aristóteles identifica ser con causa primera, argumenta la diversidad de seres por medio de la analogía, así como profundiza en la dinámica propia del ser dada en el movimiento de potencia y acto, a partir del cual se comprende la vida como el modo de ser más alto. No se deja de tocar el problema lógico del ser como cópula en los enunciados, desde donde se comprende el ser como relación. Vale señalar que desde los griegos, según Heidegger, quienes se preguntaron por el problema del ser, al buscar una respuesta en la naturaleza que tenían a la mano, se fue olvidando el ser para ocuparse, desde entonces, del ente.

En la Edad Media, los estudios sobre el problema del ser solo se dan dentro de los límites de la investigación acerca del ente, y en particular con un referente particular: el ente infinito, necesario y creador-de-todo-lo-que-es. Todos los demás entes son creados y, en cuanto 
tales, no son necesarios. Aunque, así no sean necesarios, tienen su ser, su existencia, su realidad efectiva, a partir de la cual se elabora el concepto objetivo del ente. Un problema bastante elaborado de esta época también es la diferencia entre esencia y existencia: lo que es y cómo es. En términos de los tomistas, esta es una diferencia real: una cosa es el ser en potencia (en esencia) y otra es ese ser en acto (su existencia). Para los escotistas no son dos realidades diferentes, sino dos modos distintos de la misma realidad: la existencia solo es un modo metafísico que se añade a la esencia. Para Suárez tampoco es una diferencia real, como tampoco modal, sino una distinción conceptual: lo que se da entre esencia y existencia tiene que ser de razón, porque de lo contrario serían dos entes diferentes; con la existencia cada ente recibe, en efecto y por primera vez, su ser.

De entre los filósofos modernos, el primero que llama la atención de Heidegger es Kant, porque con él se retoma el problema ontológico cuando afirma con mucha claridad que el ser no es un predicado real, es decir, que no es algo objetivo (objeto), no es algo así como una cosa ante-los-ojos: ser no es ente. Además, de los entes hacemos conceptos, pero como el ser no es un ente, no se puede avanzar en su estudio con meros conceptos, fruto de la intuición, sino que exige más bien una metodología de comprensión, más propia de la filosofía trascendental.

Habría grandes filosofías que no por ello dejan de solapar problemas fundamentales. Tal vez esto sea lo que dijese Heidegger acerca de la filosofía de Hegel, quien no supo diferenciar entre ente y ser, usando de manera indistinta ambos términos. A lo sumo, podría decirse que mientras ser hace referencia a la presencia, ente hace referencia a lo presente. De todas maneras, al ente siempre lo concibió como absoluto, es decir que lo identificó con Dios, y de ahí que su propuesta no pase de ser una ontoteología. Lo absoluto que se despliega de forma dialéctica evidencia la fuerza que lo constituye, y que a su vez se constituye por un juego de fuerzas que no permiten evidenciar fuerza alguna particular y que, en consecuencia, nos llevan al no ser de la(s) fuerza(s). La fuerza no es, puesto que ella se da en el juego de fuerzas que dialécticamente constituye al absoluto, el espíritu, que en cuyo salir-fuera de sí hace presencia y muestra su ser, el mismo ser que es pensado, no otro, de donde ser y pensar son lo mismo. 
Esta tradición occidental que pregunta y piensa el ser, pero que de inmediato lo va olvidando al encontrarse con el ente, finaliza con Nietzsche. En términos de Heidegger, con Nietzsche se cierra una época y se abre otra: acaece, entonces, otro inicio, el nuevo comienzo del pensar. Este nuevo inicio no es, de todas maneras, una ruptura total con lo que venía, porque, al fin y al cabo, el cambio de valores de una época a otra - por así decirlo- siempre ha ocurrido: a través de la historia se ha dado la transvaloración de los valores que ahora, al alcanzar uno de sus más altos puntos, se identifica como nihilismo. Si en Nietzsche el carácter de todo ente es la voluntad de poder, esta misma, en su preguntar, lo que interroga es el ser del ente.

Preguntar es un ejercicio de la voluntad, un esfuerzo por saber, señalando a su vez que una cosa es conocer y otra saber: se conocen los conceptos, mientras que con el saber se concibe el ser; se sabe lo que se quiere, en lo que uno se esfuerza. ¿Y la verdad? Es fuerza, fuerza vital que embriaga, y por ello quien más se acerca a la verdad es el artista, para quien belleza y verdad van a una. Nietzsche considera el arte como metafísica de la vida, y vida ya no como mero concepto teórico referido a lo biológico, sino como saber meta-físico y existencial, que posibilita el arte con sentido de ser en el acto de creación, esencia del eterno retorno de lo mismo. En síntesis, el ser se puede comprender como un saber vital al que se accede mejor por el arte, en el cual se descubre la verdad a fuerza de voluntad, como devenir propio de esa vida, es decir, en cuanto vivir.

¿Qué pasa con el ser?, se pregunta Heidegger. Y en su conversación con los griegos comprende que ser emerge de la "naturaleza-física" como surgimiento, develamiento, desocultamiento, desde lo que ya está (ahí, natural). El ser brota, crece, acontece como la vida, y se sostiene desde sí mismo en un decurso histórico en el que se muestra como devenir, como lo-que-aparece (apariencia), como lo pensado, y como lo que debe ser, donde el discurso lógico y científico no alcanza para expresarlo, y por ello se recurre al arte y, dentro de él, a la poesía. Gracias a la esencia poética, el lenguaje se hace morada del ser, pues allí lo mantiene y lo cuida, llevando al filósofo, ahora, a hacerse pensador.

Pensar el ser conlleva "negar" el ente: la metafísica se preguntó por el ser del ente, la nueva ontología debe preguntar por el ser desde 
el ser mismo, desde donde él mismo verdadea. Y no hay un método específico para aproximarse a él, a no ser que como método se interprete la meditación poética con la cual el ser se esencia. ¿Y cómo se esencia el ser según Heidegger? Como Ereignis, evento que acaece enlo-que-es. Vamos siendo el ser nosotros, todos y todo: lo general y lo único, lo inteligible y lo oculto, el abismo y lo que brota, lo olvidado y lo pensado, lo más dicho y el silencio. Los pensadores se hacen, entonces, poetas, no ya filósofos, porque, según Heidegger, solo en la poesía está el camino que nos aproxima a la esencia del ser.

Para este momento, los desprevenidos pensarán que la ontología se ha desnaturalizado, que abandona los cuidados de la filosofía para pasar a la cuna de la poesía; sin embargo, lo que acaece es una radicalización del objeto de estudio, a saber: el ser, el que a su vez exige una nueva manera -otro inicio, dice Heidegger- para comprenderlo. A la ontología le compete, y siempre le ha competido, el problema del ser en cuanto tal, y esto es lo que se está rescatando de nuevo: ubicar el problema en sus justos límites y bajo el horizonte adecuado, para poder avanzar. Es el momento de tener la fineza necesaria para que este reinicio posibilite una mejor auscultación de lo que hay que escuchar, de lo que hay que meditar. Precisamente el lenguaje poético nos lleva a abrirnos a otros ambientes, nos hace desplazarnos a otros espacios, nos pone de presente que hay otros horizontes de investigación, como acontece con la apuesta del filósofo argentino Rodolfo Kusch.

Aunque no parte de la pregunta por el ser, todo el pensamiento de Kusch está atravesado por esta cuestión. En el contexto expuesto hasta acá, habría que decir que este filósofo parte del pliegue ecualizado entre Nietzsche y Heidegger: el ente constituido de forma vital, que muerde el sentido del ser. En concreto, Kusch parte del paisaje latinoamericano, y esto es decir mucho, porque de entrada se debe señalar que para nada parte de conceptos: no es del concepto paisaje, sino del paisaje mismo, o mejor: es desde el paisaje latinoamericano desde donde se cuestiona Kusch, estando en el paisaje bárbaro de esta América nuestra piensa el ser de nuestro paisaje. Un ser azaroso, en el que un árbol pudo ser alga o un animal pudo ser piedra.

Si dejáramos a un lado todas las investigaciones académicas, organizadas de forma metodológica, y nos quedáramos contemplando 
este nuestro paisaje, dado en su diversidad de formas, enraizado en la vegetación agreste de montañas y altiplanos, donde la vida emerge por doquier, en el helecho gigante tanto como en esa pequeña "sociedad" de hormigas incansables, lo que nos queda es una idea de hibridación ecológica demasiado rica en sentidos y posibilidades, que Kusch sabe apañar en el Quetzalcóatl: realidad y ficción, demonismo y pulcritud, barbarie y civilización, ente y ser. No uno en oposición al otro, no uno al lado del otro, sino uno en el otro: la realidad en la ficción, el demonismo en la pulcritud, la civilización en la barbarie, el ser en el ente. No hay escisión entre los “opuestos", hay mestizaje, a favor de uno de los dos, a favor siempre de la vida, del sentimiento, de la cultura, de la fe y, en el fondo, de nuestra propia historia.

La historia de los americanos de la América Latina, o como vendrá a llamarla Kusch, de la América profunda, no es la historia de Europa, ni continuación alguna de esta, sino nuestra historia. Es una historia que se enraíza en nuestro suelo, que se alimenta del componente vegetal en el que estamos situados, que se enriquece con nuestros mitos, tradiciones y creencias, que se yergue desde nuestras más diversas culturas, sin buscar — para nada — la acepción cultural de nuestro ser. Pero por supuesto que tenemos una ontología, diría Kusch, pero no entendida en términos racionales desde conceptos y categorías abstractas ni argumentada desde los silogismos. Todo lo contrario: es una ontología nutrida por el magma vital de nuestra geocultura, que ofrece un sentido existencial a lo que hemos venido siendo: antes, en nuestra historia precolombina, y después, con el mestizaje que se nos impuso. De todas maneras, preguntar por lo que somos debe hacernos sentir el suelo que nos sostiene, con todos sus nutrientes irracionales, inconscientes y culturales, a partir de donde podremos abrirnos al horizonte ontológico que nos posibilita estar siendo de la manera como en efecto estamos.

Y es que para Kusch, no es posible (el) ser sin estar, no porque él quiera suponerlo así, sino porque eso es lo que encuentra en su investigación. Su trabajo de campo es complementado con el estudio de algunos textos que en el ámbito académico habían sido relegados, como el manuscrito del indio Joan de Santa Cruz Pachacuti Yamqui Salcamaygua, Relación de antigüedades deste reyno del Pirú, en el que se evidencia la armonía de contrarios desde los que, de manera dual, 
se presta fundamento a todo lo que es. Tampoco es que la diferencia de comprensión no permita un punto de comparación: ya se observó cómo desde los griegos se ha dado la lúdica entre ente y ser, entre ser y no-ser, o la que se dio más tarde entre esencia y existencia.

En el manuscrito de Pachacuti lo que se evidencia son las díadas caos-orden, ira-miedo, Tunupa-Tocapo, vida-muerte, que como en la cultura occidental no se puede comprender uno sin el otro: a pesar de su aparente oposición se necesitan entre sí para alcanzar el equilibrio orgánico y cósmico. De este magma emerge la también díada racional-seminal, cuyos vectores vendrán a caracterizar el pensamiento, acorde con la dirección por la que se opte, y permitirán acoplar aquella otra más profunda y fundamental: ser-estar.

Cuando el paisaje, la naturaleza, se comprende a una con el ser humano, individual y socialmente, la experiencia de lo que es y de lo que se es difiere de la de quienes han tomado distancia del paisaje y lo han objetivado: estos lo manipulan y usufructúan, aquellos lo cuidan y lo sienten de manera fraternal, conatural. Tomada la naturaleza como simple cosa, ahí ante los ojos, se transforma en útil, en instrumento; comprendida como parte esencial de lo que somos se conjura para transformar en venturoso lo nefasto. La primera experiencia es la que corresponde a lo que se experimenta, la segunda es una experiencia emocional que interioriza lo exterior. Los experimentos fomentan la mecánica y con ella se busca el "progreso", la experiencia emocional fomenta la conexión con el suelo y con ella se cuida lo vital (vivencia). Recuérdese que la ontología, que busca el sentido del ser, se ha quedado desde los griegos apenas en lo ente (metafísica) y con dicha filosofía se ha objetivizado el mundo transformándolo desde la industria en mercancía y producto, casi siempre desechable. Desde la vivencia del estar, lo que se busca es radicalizar el miedo original del estar-ahí-no-más para hallar un sentido de ser que posibilite abrir un horizonte mucho más allá del patio de los objetos como otra posibilidad ontológica.

En la mentalidad indígena, el estar se configura dentro de una metafísica biológica: huyñay, estar creciendo siempre, como el árbol. El estar tiene su propia dinámica, no quiere decir de ninguna manera una quietud estática, como a veces se le quiere malinterpretar. Kusch 
expresa que la cultura del estar fagocita la del ser, porque el fundamento del ser se encuentra en el estar. Sin este, no se daría aquel. La realidad toda es comprendida de manera orgánica, como un "infinito" ser vivo que cumple las leyes propias de la vida: tanto estar como ser no se comprenden como meros conceptos pertenecientes a un pensar abstracto y meramente racional. Estos, como todo término, hacen parte de la realidad orgánica que busca su equilibrio existencial, dentro de la que nos conducimos, en la que estamos y para la que "cosechamos" el fruto. Solo así se puede comprender por qué Rodolfo Kusch traslapa la pregunta de la metafísica y la ontología tradicionales por esta otra: ¿por qué somos vida y no más bien muerte?

La vida es fundamento transversal de todo lo habido y comprendido en el pensamiento indígena y campesino, y tal vez, ella es también el fin último de todo lo que es. Por eso, por ejemplo, se aprende no solo para tener conocimiento, sino para inscribir la propia vida en el paisaje, es decir, para incardinar nuestra propia vida en la vida total que es cósmicamente. De ahí la importancia y necesidad del rito con el que se da sentido al estar cotidiano, así como al decurso total tanto de personas - individuos - como de comunidades y pueblos en general.

En Kusch, pareciera que la ontología no se escribe en tratados ni en ensayos dignos de ser leídos desde lo académico. Está inscrita en la existencia vital de los pueblos que vierten su sentido de ser en danzas, ritos, ciclos agrarios o cósmicos. Estos evidencian la búsqueda de un equilibrio nunca alcanzado, y que pone siempre en tensión la existencia humana de cara a los dioses y su ira, o de cara a los avances tecnológicos y su "utilidad".

Desde el pensamiento indígena, comprende Kusch, que la realidad es sagrada. "Estar en el mundo" no es más que dejarse desdoblar de la divinidad viva que ordena el cosmos y de la que no podemos huir. Pero ordenar el cosmos no es imponerle un orden racional que todo lo purifica y perfecciona —en términos occidentales—, sino que es más bien una búsqueda de equilibrio entre lo venturoso y lo nefasto, entre lo afirmativo y lo negativo, entre la (mera) razón y el sentido. Las cosas jamás son meros objetos: cada una de ellas es como huaca, las anima un espíritu, tienen su "personalidad", y de ahí la necesidad del conjuro y de los ritos. La realidad no se conoce de manera objetiva, 
ella se siente, nos afecta y afecta todo lo que es. En consecuencia: el ser está. No es, sino está.

La esencia del ser se comprende en el estar, un estar que de por sí es afectivo y, como ya se dijo, orgánico, seminal, que se enraíza en lo más sagrado de la existencia, cual divinidad que todo lo inunda y todo lo subvierte en el rito de lo que es: pacha. Es verdad que en el mundo cósmico del pacha hay inestabilidad y contradicciones, además de ser por completo circunstancial e inseguro; pero así es, no hay que preocuparse por ello. La perfección y estabilidad del ser es imperfección e inestabilidad en el estar, la afirmación y seguridad del ser es negación e inseguridad en el estar, la estructura racional y lógica del ser es sentimiento y vida en el estar. Así es. Eso pasa por no ser más que semilla de la divinidad: no otra cosa es todo lo que es.

Ya se vio cómo en Heidegger el propósito se enfoca en pensar el ser, y ahora tenemos que en Kusch se trata más bien de sentir el estar. De alguna manera se da una negación del ser, no para anularlo, sino para ofrecer otra posibilidad de comprensión ontológica, lo que podría decirse —en este contexto- señalar un nuevo inicio, también, para la ontología. En este sentido, los dos filósofos no se encuentran muy lejos el uno del otro: ambos cuestionan a profundidad una larga tradición metafísica que no ha respondido sus interrogantes fundamentales y, por ello, no se ha dado un sentido de orientación para saber lo que es. Ahora bien, mientras Heidegger afirma el ser dentro de la apertura de un nuevo horizonte de comprensión hasta ahora negado (el devenir como evento), Kusch se atreve a negarlo, también desde la apertura de comprensión con la que, en América Latina, hemos sido negados (con el propósito de negar una negación para afirmarnos desde lo ontológico).

Así cobra protagonismo la negación. ¿Cómo se llega a ella? Rodolfo Kusch parte del pensamiento popular, identificado de manera despectiva como mera opinión, debido a que solo se considera como válido y científicamente validado el pensamiento culto. Por lo general se juzga la opinión como constituida por una serie de pareceres subjetivos que se alejan de la objetividad y certeza del conocimiento validado desde el ámbito científico, demostrable y evidenciable por la lógica racional que le da sustento. Pero ¿acaso, se pregunta Kusch, la realidad verdadera 
e íntegra es solo la que se evidencia de manera científica, la que se demuestra desde lo racional? Esa es una pequeña parte de la realidad, una parte de la verdad. Esta realidad y su verdad son más bien plurívocas, se dan de una y otra forma, su apariencia es múltiple y diversa, y por ello la opinión capta más esa realidad total e íntegra, múltiple y diversa, que el pensamiento culto o racional que no da crédito a emociones y sentimientos, a dioses y lo sagrado.

El discurso racional da cuenta de un mundo objetivo, ataviado de cosas, mientras que con la opinión se apañan tanto cosas como eventos, significados, símbolos, que ofrecen sentido existencial, que posibilitan un sentido de orientación a la vida en sus más diversas facetas. Conocer (desde lo objetivo) no es suficiente, se hace necesario el saber (existencial), y en este último la opinión ofrece aportes que son relegados, desechados, por el pensamiento culto y racional. Tenemos, entonces, acá, otra dualidad: ciencia y natura: objetividad y conocimiento científico frente a naturaleza verdadeante y opinión. Se piensa el ser, se siente el estar. La ontología (del ser) es propia de ese discurso objetivo de la ciencia, mientras una ontología del estar pertenece a un antidiscurso más propio del sentido existencial de la vida (vivencia).

Aunque Heidegger no se da cuenta, también está del lado del estar: él insiste desde sus primeras obras no en la pregunta por el ser, sino en la pregunta por el sentido del ser, y el sentido es menos racional, menos objetivo, más connotativo, más emocional. Quizá por esto Kusch comprende un solo pensar que puede ejercitarse de dos modos: culto y popular, objetivo y emocional. El pensar meramente racional no apaña toda la verdad, es incompleto, como es de seguro incompleta la sola opinión, pero Kusch le sabe dar el puesto a la opinión, sin desdeñarla, como a su modo también lo hizo en su momento Heidegger.

El pensar completo posibilita comprender el mundo completo, no solo una parte de él. Muy pobre resulta ver solo objetos. Comprender empieza por comprenderse desde lo interior y abarcar, luego, la totalidad culturalmente, es decir, desde una determinada experiencia, o mejor, vivencia. Para Kusch, la cultura se arraiga en el suelo, pesa desde lo seminal, cual semilla que va creciendo pacha y nos posibilita 
ver una montaña pero además comprenderla como maestro o abuelo (achachila). Esta forma de comprensión no es subjetivista (en contra de la objetivista de la ciencia); en Occidente no habría términos para designarla, pues los que tenemos: mística, trascendental, mítica, mágica, ya tienen el dejo despectivo con el cual el pensamiento ratiocéntrico la caracteriza.

Se podría hablar de ontología cultural o de ontología vitalista, inclusive de ontología ancestral, pero ninguno de estos términos encierran todo el sentido íntegro con el que se quiere abarcar la realidad completa en la que quepan los objetos y los dioses, los conceptos y las fantasías, los sentimientos y las sentimentalidades, las certezas y las opiniones, en fin, la realidad total, la totalidad de todo lo que es, porque no solo es lo científico sino también es lo sagrado, porque no solo acontece el devenir sino también lo que está. Aun en un contexto antropológico —como era el interés de las últimas investigaciones de Kusch - se siente el suelo ontológico que sustenta su pensar. En esta última etapa de su vida se vislumbra un sentido que ya no separa tanto objeto de sujeto o razón de sentimiento, más bien posibilita su unidad y con ello señala el estar-siendo.

La posibilidad de ser es estar-siendo, y las posibilidades del ser humano se dan en su estar-siendo. Nuestro vivir es mera semilla que patentiza el suelo desde el que estamos siendo desde lo cultural: nuestra comprensión va más allá de lo ontogeocultural, es justo así porque la realidad es así, su esencia es diversa: objetiva, seminal, sentimental, sagrada... todo lo que deviene en su estar-siendo.

¿Qué pasa con la ontología? ¿Debe reducirse a meras categorías racionales, a conceptos abstractos, a nociones lógicas que no se relacionan con la experiencia existencial de lo que somos y de cómo estamos? Si el mismo Heidegger cuestionó el inicio griego del planteamiento del problema del ser, nosotros, desde América Latina, ¿no podríamos encontrar otra posibilidad para el desarrollo de la pregunta por el ser?, ¿nuestro horizonte de comprensión no se abre acaso a un sentipensar que difiere incluso del "segundo inicio" planteado por Martin Heidegger? ¿Cuál es la estructura con que se constituye la apuesta ontológica de Rodolfo Kusch desde unas categorías fundamentales halladas en el pensamiento filosófico latinoamericano? 


\section{La negación como posibilidad de vida}

¿Cómo posibilitar el camino a seguir para una ontología que se enraíce en la América profunda de Rodolfo Kusch? ¿Con qué método nos aproximaríamos? De seguro es el mismo Kusch quien nos señala la senda cuando propone su "lógica de la negación". Ya analizamos su obra La negación en el pensamiento popular (2003c), donde al inicio caracteriza el pensamiento popular con la opinión. Desde Platón, la opinión ha sido mirada de forma peyorativa por el pensamiento culto; sin embargo, sucede lo contrario si nos ubicamos en el pensamiento popular: para el pueblo, la opinión ofrece seguridad para vivir y diversas posibilidades de explicación de la realidad. Y es que, seguramente, la realidad misma es plurívoca, dice Kusch.

El taita Anastasio Quiroga, por ejemplo, encuentra en la natura la matriz organizadora de la naturaleza toda, a la que todos los seres deben seguir, y el yatiri Felipe Cotta encuentra en Dios ese principio ordenador de la realidad. Natura y Dios fungen acá como operadores seminales: ordenan de manera cualitativa el mundo, legitiman, a su vez, dicho orden, y ofrecen sentido existencial a una comunidad. Dichos operadores hacen parte de la forma como se da el pensamiento popular, que se caracteriza como emocional y cuyo "instrumento" comunicativo y argumentativo es la opinión, porque esta ofrece sentido a los quehaceres del vivir cotidiano con significaciones que hacen efectiva la posibilidad de vivir.

En el pueblo, los que saben ofrecen explicaciones que son más propias de horizontes de comprensión emocional que racional o, en último caso, no les queda más que decir "así es", no porque no haya más que decir, sino porque ese "asî" emerge del centro sagrado con el cual palpita la realidad que jamás podrá ser concebida —en este contexto- como mero objeto, cosa o instrumento "ahí, a la mano". Dichas explicaciones son interpretadas por Kusch como antidiscurso porque niegan las cosas como meros objetos para poder comprenderlas, más bien, dentro del horizonte de sentido. Un sentido simbólico, místico o sagrado, que ofrece la razón de ser de lo que nos acontece, una razón de ser existencial, "fundante”, dice Kusch, porque con él se funda la existencia. 
Dar fundamento sagrado a las cosas, "iluminar" con sentido existencial el acontecer cotidiano, en esto radica el pensar. La afirmación de verdades teóricas, fruto de conocimientos conceptuales, muchas veces abstractos, que no tocan el fondo de la existencia personal, no es nada, mucho menos pensar. El pensar popular niega las cosas tal cual aparecen de modo objetivo, para poder ofrecer una explicación significativa que funde la existencia con sentido sagrado, profundo, existencial. La negación es, pues, esencial al sentido; sin negación de las cosas como tales, no se da el "verdadero" significado de la vida. En términos heideggerianos se enunciaría así: sin negación (superación) del ente, no se alcanza el sentido del ser, el sentido del ser pasa por la negación del ente.

La opinión, como un parecer de lo que es, permite que aparezca el sentido sagrado de las cosas, de la realidad total. Desde la lógica silogística no puede darse semejante paso, y por eso Kusch lo llama "trampa lógica" para vivir. La negación de la objetividad científica, en el sentido que acá se está comprendiendo, será el único camino en que la vida tendrá un sentido y se llenará de significaciones. ¿Y por qué este sentido y estas significaciones? Porque la realidad es mucho más compleja de aquella que nos presenta la ciencia: esta solo nos ofrece una parte de la realidad, la que pertenece a los cosas frías y desamparadas, a objetos cuantificables sin otro significado que el de ser observados y entendidos de manera racional, con una lógica que a veces no va más allá de lo formal ni de la matemática.

La realidad es mucho más rica, sensiblemente diversa, exige explicaciones mucho más profundas de las que ofrece la mera razón. Se transforma, así, la razón, en algo irracional, a la que le sirve una lógica científica corta para explicar la realidad total. La opinión se comprende, entonces, como íntegra desde la perspectiva racional, animada por una negación lógica y necesaria para comprender la realidad íntegra.

"Así es", expresa la opinión del yatiri, del taita, del abuelo, en el contexto de su sabiduría ancestral. Y se está sin más. Por eso el estar también ofrece un significado profundo, un sentido de ser. Estar, como mera apariencia cuya esencia sería el estatismo y la pasividad que se les ha achacado a los pueblos indígenas, es un concepto muy pobre. El estar tiene toda una riqueza simbólica y vital que se funda en la lógica 
de la negación y que pasa por un sentido vital, como se verá más adelante. No es la verdad lógica la que persigue el saber ancestral, sino la verdad íntegra, total, que acoge los diversos vectores de la existencia, y que es dinamizado por los operadores seminales. "Así estamos”, también habría que decir.

Nuestro estar está atravesado, precisamente, por esta realidad diversa e íntegra, no solo se constituye por ese vector lógico y racional que una determinada cultura ha querido imponer. Por ello la afirmación de Kusch acerca de que cuanto más se observan cosas menos dioses se ven, y cuanto más se siente lo sagrado menos sentido tienen los objetos. Aun los objetos siendo tal cual son, es decir, siendo las cosas que son, no significan eso nada más para quien comprende la realidad de forma íntegra: los útiles se convierten en in-útiles cuando su sentido es mucho mayor al que lo reduce a lo simple útil.

El camino de la negación resulta ser, al final, el método propio para existir, para vivir con sentido. Aunque Kusch la compara con la admiración, con la duda y con la epojé, la lógica de la negación es más fundamental que estos métodos, precisamente porque es el método de la existencia vital. No se trata de hacer filosofía conceptual, de lo que se trata es de disponer de las herramientas necesarias para el camino de la vida, para existir con sentido.

Sin la negación no se comprenderá como se debe el estar, y sin estar, la ontología se queda en un plano superficial, porque trataría solo del ser, y nada más. Sin embargo, en Kusch, es el estar la condición que posibilita el ser, y si se coarta esta posibilidad se crea resentimiento. Si no se existe con sentido, se existe, entonces, resentido. Esta es una de las razones por las cuales se evidencia que la verdad existencial es mucho más que una verdad matemática: la negación y el resentimiento confirman la verdad propia de la existencia, de la vida con sentido. Se puede seguir creyendo en la ciencia y sacrificarnos a nosotros mismos, dice Kusch, o creer en una verdad más íntegra que la científica y dar paso a las diversas posibilidades existenciales que tenemos.

Carlos Pagano, en su tesis doctoral Un modelo de filosofía intercultural: Rodolfo Kusch (1999), dedica un capítulo a la lógica de la negación. Allí expresa que, aunque las publicaciones de Kusch sobre la negación datan de 1973 y 1975, no se puede pensar que sea porque solo 
hasta ese entonces él la haya puesto en juego, idea acorde con los estudios llevados por Daniel Toribio y Alejandra Trorelli, quienes consideran que dicha lógica es el hilo conductor de todo el pensamiento kuschiano.

En efecto, si tomamos tanto sus últimos escritos como los primeros, nos encontramos con una persistente unidad, más allá de las diferencias expresivas de maduración y de los pensadores con los que dialoga. La negación se entrama con su impulso intercultural con el estar y sus preanuncios. (Pagano, 1999, p. 161)

Según Pagano, la negación en Kusch comporta dos aspectos básicos: el primero se refiere a la insuficiencia bibliográfica, en el ámbito académico, que no responde a la experiencia vivencial del pensamiento popular, y el segundo, a una comprobación efectiva de una negación operante en el propio pueblo, así como en los mitos y símbolos de las culturas latinoamericanas. Dicha negación también se da en la circunstancialidad, que no se toma como mero accidente que depende de una sustancia sino que es, en esencia, sustancial: las circunstancias por las que estamos como estamos no son cosa accidental sino que hacen parte de la esencia de nuestro ser, son sustanciales en nuestra existencia. Por ello se llega a negar la sustancialidad de la sustancia que deja por fuera la accidentalidad.

De lo anterior se desprende que no se pueda considerar la negación como un simple método, por ejemplo, para legitimar la intuición o - acá tendría que decirse - una ontología del estar; "es ante todo resultado de un aprendizaje cuyo magisterio Kusch reconoce al pueblo mismo" (Pagano, 1999, p. 164), porque es el pensar popular el que capta el favor o disfavor con que deviene la vida y no solo un mundo de cosas y útiles. Sin embargo, la negación no es una lógica del pueblo y nada más, de igual modo se evidencia en el pensar culto, por más que este lo quiera evitar.

En el cruce de estos dos vectores (popular y culto) puede darse lo común a los dos modos del único pensar y señalarse, allí, la universalidad del pensamiento, que incluiría la universalidad del pensamiento indígena y popular. Según Pagano, “es imposible para Kusch desentender una 
dirección de la otra" (1999, p. 165), ni de manera exclusiva el mundo de los objetos que nos llevan a una economía fruto de relaciones de pura materialidad ni solo la sacralización de la vida y de las cosas.

Es necesaria la integración real de los dobles vectores del pensar: de la razón y su lógica formal y matemática, y de la barbarie del sentimiento y lo sagrado, se trata de la conjunción de ambos. La negación es fundamental para desustancializar la ratio con sus seguridades y así dar lugar a las posibilidades de la existencia, de la vida y de su suelo, en el sentido de la semilla que germina negándose a sí misma. Se pierde el sentido cuando se topa uno de forma inexorable con la disyuntiva de civilización o barbarie, pero ninguna de las dos se da de modo absoluto, y debe comprenderse el juego que las intersecta y las conjuga.

El terror ante lo bárbaro impide ver que también hay terror en la civilización cosificada por el racionalismo y la economía. Sin embargo, el pensamiento culto sabe argumentar a su favor, y tal vez por ello no queda más que decir "así es”, cuando se está al otro lado, a sabiendas que ese "es" implica el estar que confía en un fundamento, otro, que permite comprender el mundo sin el afán de poder, riqueza o perfección "objetiva".

A una negación que hunde sus raíces en la vida no le queda más que fagocitar lo afirmado. Fagocitar, por ejemplo, la barbarie con que se nos niega, para poder afirmar nuestra cultura, aun a pesar de que luego se nos tache de culturalistas, que es otra manera de continuar negándonos en nuestras posibilidades. En este contexto, se entiende "la fagocitación como 'negación de la negación' de la pretendida barbarie” (Pagano, 1999, p. 168), que se achaca a pueblos colonizados, y la negación como cuestionamiento al andamiaje cultural, político y económico que excluye las posibilidades de ser de esos pueblos.

Negar dicho andamiaje excluyente es negación de otra negación para posibilitar la afirmación o el tercero incluido ${ }^{1}$, que es el caso de la montaña que se comprende como abuelo, de la sabiduría al leer

1 Si la lógica de la afirmación, propia de la lógica formal, promulgaba el "tercero excluído" (porque o se afirma o se niega algo, y no puede haber otra posibilidad, como se evidencia mejor en la lógica matemática), Kusch le apuesta a una lógica de la negación que, en caso de habérselas con un "tercero" sería 
hojas de coca o del auto nuevo que se manda a bendecir. "La negación no se da solo en el indio, es una lógica de carne y hueso, con sonco - corazón- incluido, que impregna la vida de todo nacido de mujer" (Pagano, 1999, p. 169). La negación se presenta de forma universal, pero la negación de la negación es un proceso que se evidencia en carne y hueso en América Latina y en otras regiones del mundo también colonizadas, cuando se dan a la búsqueda de sus posibilidades desde sus más propias raíces, revaluando los orígenes que les corresponden, es decir, su semilla.

La seminalidad representa otra recíproca de la lógica de la negación. Interdependientes, esta funciona como tal porque el pensamiento no opera según una mecánica casual, sino según la ley de la semilla: El soporte funcional de un pensar seminal es la negación en tanto "se concreta a una negación de todo lo afirmado", pero como requerimiento de una unidad conciliadora de la oposición "que trasciende y que ha surgido al margen del yo como germen”. (Pagano, 1999, p. 169)

La negación germinal, en este sentido, es una negación radical: de radicalidad existencial. Dice Pagano, que responde a una realidad signada por opuestos, en los cuales se juega noche y día, muerte y vida, lo nefasto y lo venturoso: toda la realidad trasunta contradicción, en particular si nos detenemos a pensar la realidad cotidiana. Realidad del quehacer sencillo y doméstico que no esconden los indígenas, los campesinos ni la señora del barrio que en las tardes saca su puestico de arepas a la esquina, trabajos en los cuales se enmugran las manos, los pies, el rostro, con el polvo de la tierra que les da para vivir con lo apenas necesario y según tradiciones propias de cada región, de cada lugar.

He aquí por qué el estar no oculta la sangre cultural que lo alimenta y por qué Kusch vendrá a hablar de una geocultura (que es 
limpiada por el discurso higiénico del ser). "La reciprocidad ya mencionada entre cultura que habita una tierra - geo- y sostiene la negación del pensar popular advierte que esta, por su parte, funda una cultura que no se separa racionalmente del mundo, es decir, funda una geocultura" (Pagano, 1999, p. 170), que va en consonancia con una lógica guacha (huérfana, desmadrada, según el significado quechua). Esta se libera de la placenta logocéntrica y racional para nutrirse de la vida toda, íntegra, con sus contradicciones naturales y sus aporías de sensibilidad existencial que llevan, de todos modos, al encuentro con lo sagrado, y al encuentro con la tierra, como si también fuera un encuentro sagrado.

En este contexto ya no se buscan conceptos abstractos ni categorías absolutas que den cuenta de la realidad, sino más bien nociones básicas y términos más concretos que den cuenta de nuestra realidad más propia. Esto, por ejemplo, "incide de lleno en la ontología: el ser, en su dureza, queda afectado por una mutilación básica. El gerundio siendo devalúa su absolutez y 'lo sumerge nuevamente en el estar'” (Pagano, 1999, p. 171).

A pesar del enriquecimiento de la ontología heideggeriana con los nuevos aires de una comprensión del ser como evento que acaece en lo que es, que se esencia en la verdad más suya, y que al final toma una distancia radical con el ente (bajo cuyo sentido estuvo atrapado en la metafísica), no puede abandonar ese horizonte lógico de la racionalidad occidental en la cual los conceptos y categorías asépticas de todo lo concreto y particular terminan no tocándose con lo cotidiano, con lo existencial de la vida concreta, que es lo que da sentido a la vida en la que devienen nuestras posibilidades de ser. La ontología de Heidegger, a pesar de esa grandilocuente elaboración fenomenológica y hermenéutica que rompe los esquemas tradicionales de la metodología científica, no se libera de los principios universales de la razón que Occidente le ha impuesto, y por ello sigue anclada en la tradición de la cultura griega que se autoconsidera fundadora y dueña de la filosofía universal en cuanto eurocéntrica.

El problema del ser no puede continuar reducido por los límites que esta razón le impone, porque así no da cuenta de todo lo que es. Una elemental noción de ser ya debería dar cuenta de la realidad total, 
comprendida desde las raíces de lo que somos e incluir la diversidad del mundo en el que estamos, lo que exige, seguramente, además del pensar que medita el acaecimiento ontológico en el que deviene el ser, también, un sentipensar, en esencia ontológico, que asume la riqueza del estar desde el que se señala el ser, inclusive negándolo.

¿Hasta qué punto asume este riesgo Rodolfo Kusch? Hasta los límites que le permiten el estar-siendo. Hasta este nivel llega Kusch. Niega el ser, como es obvio, no de forma absoluta, pues no sería consecuente con la tradición cultural y los saberes propios de América Latina. Lo niega hasta el punto donde el ser pierde esa absolutez que le imprime su tradición ratiocéntrica, y hasta que gana un polo a tierra, un suelo, que le es aportado por el estar. De allí la fórmula estar-siendo "como síntesis de resistencia a imposiciones culturales y a sus dimensiones económicas, sociales, políticas y hasta religiosas" (Pagano, 1999 , p. 171), que posibilitan el vivir, una y otra vez negado, pero sin que alguien se atreva a negar dicha negación.

Con la negación de una negación se adquiere un sentido positivo de la misma, más allá de la lógica formal. Pagano recuerda el caso de Martín Fierro cuando es castigado y echado a la frontera para servir en el ejército contra los indios, y entonces canta cómo ha sido tratado por no ir a votar, ya que el Estado nunca le ha dado nada, oponiéndose así al sistema impuesto, negando la negación con que es negado. Fierro muestra un desgarro interior, un resentimiento. Sin embargo, gracias a este resentimiento él se mantiene consciente de lo que le acontece y de su propio estar, proponiendo así una actitud de estar siendo.

Solo por ese resentimiento, el estar siendo deviene y se mantiene. "El resentimiento despeja la posibilidad existencial de la propia afirmación. La lógica de la negación adquiere así un neto sentido positivo" (Pagano, 1999, p. 173), por el cual uno mismo se toma en serio y se hace tomar en serio, es decir, por el cual la existencia se toma en serio. Es lo que se concluye de los yatiris y campesinos con quienes conversa Kusch: Anastasio Quiroga, Felipe Cotta, Tata Mauricio, Ceferina, Sebastiana, o personajes como Martín Fierro o Guamán Poma de Ayala. Todos ellos cuestionan la afirmación desde la que son negados, para afirmarse desde la vida. La afirmación es, siempre, afirmación 
lógicamente racional, propia del pensamiento culto, es decir, argumentada como es debido, con objetividad científica.

"El pensar popular, con su vilipendiada opinión, tiene el efecto de una cáscara de banana bajo el pisar autoconvencido de la razón causal" (Pagano, 1999, p. 174): golpe certero como el buscado con la negación de la negación. Vale insistir que ella no implica la intención de negar-en-absoluto — destruir- todo proceso de afirmación racional; lo que se busca es que la afirmación sea inclusiva, de tal forma que asuma lo que ella misma niega. Lo que se busca es salvar la integridad de la realidad tal cual es, no solo tal cual se la puede demostrar o argumentar.

En el de fondo, la realidad es, pero también está, y ello ya señala otras posibilidades de comprensión que el pensamiento "afirmativo", culto, no se había permitido. Será, entonces, gracias a este primer gran peldaño que nos ofrece la lógica de la negación, que se posibilite una ontología que rompa los límites de la razón logocéntrica afirmativa y que avizore una centrada en la vida, donde se señala al estar como suelo del pensar, propio de una filosofía encarnada en las culturas latinoamericanas y en su diversidad enriquecedora.

Es evidente, entonces, que "la negación kuschiana no es una simple concepción de Kusch ni clave única de su pensamiento, pues aquella no termina en sí misma" (Pagano, 1999, p. 181); se trata de un paso intermedio entre pobreza o indigencia ontológica —en nuestro filosofar- y la comprensión profunda de lo que somos, en cuyo avance podemos optar por pensar una ontología desde el estar - y en nuestro caso particular, desde el estar latinoamericano-, enriquecido de manera vital $-\mathrm{o}$ seminal, como se prefiera-. Como lo señala Pagano renglones más adelante: "No se trata de que la negación tenga sentido en sí misma, como tampoco el estar lo tiene". De lo que se trata es de captar la realidad existencial que está mejor vivenciada por el pueblo, aun a pesar de que la cultura urbana "civilizada" lo mande a la trastienda, al muladar, por falta de objetividad y exceso de sinrazón.

Si la negación fuera término en sí, estaríamos ante el escepticismo absoluto. La actitud del pensar en general — del cual el culto 
o científico no es más que un modo, y este reductivo por cerrar la tercera posibilidad - apunta a la revelación con vista a salvar el vivir. (Pagano, 1999, p. 182)

La vida es el telos al que apunta la lógica de la negación. No se trata de negar por negar. Se trata de encontrar el fondo (el suelo) del pensar, que de alguna manera es un camino contrario a la filosofía, en el sentido de que esta busca superar la gran trascendencia existencial por aquella que se limita a los cánones de la razón, alejándose del simple vivir, según explica Pagano, porque, por ejemplo, en la interpretación que hace Heidegger de los zapatos en el cuadro de Van Gogh, no deja de hablar la filosofía, es decir, la razón, pero falta la voz de la aldeana, la dueña de los zapatos, con su decir popular, con su opinión. Sin embargo, no es que falte la voz de la aldeana como texto lógico y racional del habla social, no, lo que hace falta es la voz como expresión de una experiencia vital de la aldeana que usa sus zapatos para la labranza o cualquier otro trabajo; lo que hace falta es el suelo que da vida a la presencia de esos zapatos y en el que germina la semilla de una determinada situación en la que se juega la existencia de un ser humano concreto, aquella aldeana.

Seguramente por esto en Kusch no son asiduas las citas de textos de otros filósofos, ni siquiera de Heidegger, a quien leyó con detenimiento. Aparecen aquí y allá, de manera directa e indirecta, citas del hablar campesino, popular e indígena, y en su última obra más que en las anteriores, porque debe darse la "negación" de la filosofía para posibilitar el pensar (como Heidegger apenas lo vislumbró y lo aplicó a la metafísica para avanzar en el ámbito ontológico).

¿Qué podemos concluir en esta línea? Primero, que Rodolfo Kusch radicaliza la negación como apuesta metodológica desde la que es posible cuestionar esa tradición afirmativa de la cultura occidental con la que relega lo negativo, visto desde ese horizonte ratiocéntrico que impone como parámetros universales lo que es particular de esta cultura. En Kusch, la negación inicia siendo una apuesta solo metódica que niega las cosas para encontrar lo que hay "debajo" de ellas, para negar los objetos buscando develar lo "sujetivo" que los anima, para negar "la razón" y así abrirse también a los sentimientos y las emociones que 
enriquecen nuestras acciones y que señalan un estar. Estar como sentido al que apunta la manera como nos encontramos desde lo existencial en el mundo.

Segundo, y siguiendo lo anterior, es el avance de lo metódico a lo metodológico, al aplicar la negación al mismo hecho de pensar, de filosofar, de habérselas —en términos de Xavier Zubiri- con la realidad íntegra, la que no podemos asumir como afirmación ingenua sin preguntarnos por el ámbito cultural desde el cual estemos creyendo dicha realidad como tal. Los prejuicios a priori con los que de antemano miramos la realidad nos conducen a continuar "citándola" sin sospechar siquiera el trasfondo, también real, que la anima, y desde el cual se comprende desde lo emocional, debido a que esta también es su naturaleza.

Solo una mirada crítica sobre los objetos posibilitará que emerja de ellos mismos lo no objetual. Esto es lo que los hace estar ahí como están y que les imprime ese su ser y esencia con el que aparecen y se develan verdadeantes. Por último, en Kusch, con el ejercicio de la negación, la ontología va mucho más allá de la comprensión del ser, entendido este ya dentro de la tradición metafísica (como ente) o ya dentro de la nueva tradición ontológica (como acaecimiento en el que deviene todo lo que es), y se enriquece con un sentido vital, seminal y de fondo existencial. La negación de la esencialidad del ser — por decirlo en tales términos-, deviene en una comprensión existencial del mismo, en el que desempeña un papel fundamental el estar.

Metódica, metodológica y existencialmente, la ontología kuschiana avanza sobre la filosofía, en general, y sobre la ontología, en particular, propias de la investigación con la cual la cultura occidental ha estudiado el problema del ser, tanto a nivel de la metafísica como de la ontología. Si con Heidegger el problema del ser había regresado a los presupuestos originales de la antigua Grecia, proponiendo un nuevo inicio para asumir este problema de manera novedosa y desarrollar un sentido que se libera del ente para ocuparse del ser en cuanto tal, con Kusch el problema del ser resulta cuestionado de fondo porque ni en sus presupuestos originales ni en sus ulteriores desarrollos se ha liberado de la tradición ratiocéntrica o logocéntrica propia de la cultura occidental. Demasiado preocupada, esta última, en avanzar en 
investigaciones científicas, que por su esencia solo buscan la objetividad y la demostración argumentativa de sus productos, sin posibilitar el ejercicio de un pensar íntegro que valore la complejidad de todo lo que es y que asume, además de lo objetivo y lógico-matemático, también lo emocional y lo sagrado.

Como se vio, en la opinión, tomada como forma de ser del pensamiento indígena y popular, hay una gran riqueza de saberes -más que de conocimientos- que posibilitarán una ontología más amplia, más profunda y más existencial, de lo que hasta ahora ha logrado la llamada filosofía universal.

\section{La vida como presupuesto del estar}

El camino a seguir quedó señalado, entonces, con la lógica de la negación. Y la negación apunta al hecho de vivir. La vida ya resulta fundamental desde la primera obra de Rodolfo Kusch. Recuérdese que allí, a propósito del mestizaje, indicó que su símbolo era el Quetzalcóatl, pero que este se inclinaba más hacia lo emocional, hacia lo vital, que hacia la limpidez racional y analítica. Es evidente que Kusch no estaba haciendo referencia en manera alguna a un concepto de vida ni a una categoría metafísica para fundamentar su discurso, se refiere al puro hecho de vivir, al acto en el que la vida se presenta de hecho, tal cual. El ejercicio por el cual negamos las afirmaciones con que de modo teórico y práctico se nos niega, no es para poder argumentar una teoría sobre la vida, sino para poder afirmarnos en lo vital, para que se dé, en efecto, el hecho de nuestra existencia.

Bajo las presentes reflexiones teóricas que nos permiten aproximarnos a las categorías fundamentales de la ontología kuschiana hay un suelo real y efectivo, un sustrato vital y concreto, que hace parte integral de dicha apuesta ontológica. La ontología de Rodolfo Kusch no tiene como objeto de estudio al ser en cuanto tal, ni se reduce al estar como novedad teórica que pueda argumentarse de una u otra manera. La ontología de Kusch se levanta sobre un presupuesto que alimenta y acompaña toda su propuesta teórica: el hecho de vivir, la vida en cuanto tal. Esta sí es la novedad. Todos los aportes teóricos, 
de seguro, son valiosos para los estudios que se avanzan en la academia y fuera de ella, pero en ninguno insistiría Kusch como en el hecho puro de vivir.

Las categorías y los conceptos, teóricos y abstractos, le pertenecen a esa tradición ratiocéntrica que Kusch tanto cuestiona, y por ello siempre está señalando ese magma vital, ese mundo de emociones, incluido el resentimiento, esa existencia ambivalente y contradictoria, que supera cualquier apuesta teórica. Al filósofo argentino le interesa es la realidad íntegra y compleja desde la que emerge el sentido existencial, pues está claro que este jamás se alcanzará por medios conceptuales.

La vida comprendida como el hecho puro de vivir es lo que da cuerpo a la ontología de Rodolfo Kusch: la vida como sustrato preconceptual, como hecho existencial, como insumo para la posterior teorización (antropológica, ontológica o en el campo que sea). La vida misma antes de su concepto y de su categorización abstracta en la que ya no se encontraría sentido existencial, la vida propia de la "gran historia" que cada ser humano va tejiendo en la cotidianidad, y tan propia de ese "monstruo" que se agazapa en la barbarie del paisaje y que se recrea en nuestro arte autóctono o precolombino. La vida encarnada y palpitante, la vida que no se urbaniza en la ciudad, que se mantiene con ímpetus inconscientes y a veces oscuros, lo telúrico, que se radicaliza en la semilla para tener la posibilidad de germinar. Esta vida es la que da todo el sentido y abre los diversos horizontes de comprensión ontológica para Rodolfo Kusch.

El mestizaje cobra así su más alto sentido. No se reduce a la hibridez conceptual, por ejemplo entre ser y ente, para iluminar la diferencia ontológica, u otras similares, como entre esencia y existencia, o entre mundo y universo, entre tantas otras diferencias significativas que le dan solidez conceptual a los discursos teóricos. Tampoco se trata solo de mestizaje de razas, como ya lo apuntó Kusch, sino de ese mestizaje de paisaje y ser humano; es decir, de barbarie inconsciente y monstruosa con la "razón pura" de la mente humana que conceptualiza, de magma vital íntegro — seminal - con meditación espiritual argumentada desde lo racional, mestizaje complejo que evidencia la riqueza de la realidad total, de todo lo que es. En efecto, la ontología de Rodolfo Kusch no es una apuesta teórica, y nada más; es una apuesta 
existencial que busca un sentido también existencial, desde donde se comprende cómo el hedor cobra también protagonismo.

Ya se anotó cómo en Kusch, el paisaje y lo telúrico implican que la universalidad de los conceptos carece de sentido, porque sentido es, siempre, sentido-vital, de y para la vida, en función de la vida, y la vida total: germinal en la semilla, en la vegetación y el paisaje, vida animal y humana, pero también la vida de los ríos y montañas, la de las nubes y las piedras, la del universo todo aunque aparezca inerte. Todo está impregnado de vida, hasta la misma muerte, porque no hay nada que no sea ira divina, actuar divino que se realiza en el mundo en dos vectores que se complementan (Tunupa y Tocapo) y que siempre están a la búsqueda de equilibrio y armonía, y que para lograrlos se hace necesaria aquella conjuración que mantiene vivas las más diversas posibilidades de ser (fruto).

Estas posibilidades tocan a la vida germinal, o sea, a lo que Kusch llama "el puro hecho de vivir", lo "no más que la vida", lo seminal e innombrable. Ello es "alcanzable" solo por el pensamiento cuando este busca el fondo o lo profundo de la vida misma. Para esto no hay afán ni meros objetos ni causas de causas por más naturales que se conciban (Pérez, 2006, p. 113). El sentido tiene, pues, un suelo: la vida, desde donde se abren las posibilidades de ser y desde donde se comprenderá el estar.

En América profunda Kusch presenta su concepto de fagocitación. Andrea Bocco realiza un breve estudio al respecto. Como neologismo kuschiano, fagocitación remite a una acción orgánica que, en lucha contra las enfermedades, se digieren cuerpos extraños. "Así, la fagocitación implica enfrentar lo extraño para incorporarlo, sin destruirlo, y ejerce una acción de preservación, de sanidad” (Bocco, 2002, p. 96). Según la autora, Kusch tuvo en cuenta estos dos elementos: incorporación de lo extraño y acción curativa. El primero de ellos se da en el momento del "descubrimiento" y conquista de América, que a su vez genera el segundo, la búsqueda de equilibrio sobre lo impuesto, como reacción natural curativa, respondiendo así a la necesidad existencial y práctica de sobrevivir.

El mismo Kusch considera que la fagocitación se da en el terreno de lo invisible, en el umbral de la conciencia histórica, en el plano 
donde se disuelve la pequeña historia para dar paso a la grande, en plexo del instinto. "La fagocitación no es consciente sino que opera más bien en la inconsciencia social” (2003a, p. 197), de donde se deduce que es un "mecanismo" incorporado de manera natural para que pueda darse la vida.

Bocco considera que, además de este aspecto, la fagocitación también se liga a prácticas preexistentes del pensar americano, una especie de "ley primitiva" que no segrega o excluye, sino que asume e incorpora, y así no elimina lo extraño sino que busca ganar cierto equilibrio existencial. Fue lo sucedido con el Quetzalcóatl, y es lo que sigue dándose en las prácticas del pensamiento latinoamericano: no se rechazan los pensamientos de otras culturas sino que se les va incorporando en la mentalidad que se tiene, y de ahí esa actitud intercultural que nos caracteriza.

Sin embargo, no se trata solo de un ejercicio mental; es una práctica existencial que no es exclusiva de América Latina, es un mecanismo universal con el que se busca mantener la convivencia entre propios y extraños. Mecanismo que no sigue la esquematización de otredad en un horizonte de centro-periferia, sino donde se alcanza un alto nivel de mestizaje y de convivencia de los opuestos. "Se trata de la contaminación de lo pulcro por lo opuesto, lo hediento que es América” (Bocco, 2002, p. 98), la hibridación existencial que posibilita, no la anulación de la vida, sino, al contrario, su enriquecimiento, sobre la cual se pueden elaborar diversas interpretaciones teóricas propias de las disciplinas sociales y humanas.

Kusch piensa la categoría de la fagocitación en relación con lo “existencial”, pero también la advierte vinculada a los mecanismos, las estrategias y las operaciones que produce el sujeto (social) en el marco de una cultura. Justamente, la incorporación de esta categoría al "mero vivir" sustenta el sentido epistemológico y social que podemos leer en ella. (Bocco, 2002, p. 99)

Desde el contexto de la vida académica, la línea que se sigue es esta de la fundamentación teórica con la que se generan conceptos y categorías, 
además de redes de conceptos y categorías. Y aunque estos enriquecen la realidad interpretada que se quiere comprender, van tomando distancia del mero hecho de vivir, de la experiencia existencial, del encuentro ecológico con los diferentes participantes del mundo-natural en que estamos incluidos seres humanos, paisaje, divinidades, etcétera.

Rodolfo Kusch le apuesta a la complejidad existencial, que no niega ni anula los marcos teóricos que enriquecen y posibilitan nuevas epistemologías para fundamentar, por ejemplo, un otro pensar como el que él mismo propone, pero se centra en aquella, en la existencia vital e íntegra misma, para la cual no es suficiente el ejercicio teórico de la debida argumentación racional, pues exige la práctica de procesos vitales de comprensión en los cuales la racionalidad es superada por la emocionalidad. Por ello, en Kusch puede hablarse de una ontología vivencial o, si se quiere, existencial, que de alguna manera también fue la propuesta de Martin Heidegger cuando expuso que el problema del ser era mejor comprendido por la poesía, aunque para el filósofo argentino todavía era necesario ir más al fondo, hundirse en el suelo orgánico, "anularse" cual semilla que se niega para poder germinar y producir su fruto, sentir la vida en su más simple y humilde condición.

Sin embargo, lo anterior no lo logró comprender Andrea Bocco, para quien la fagocitación comporta una "vuelta de tuerca" en el análisis discursivo. Es verdad que al "pensar los discursos en consonancia con esta categoría posibilita ver el revés de la trama” (2002, p. 100), como es evidente. Y también es cierto que a partir de la fagocitación se permite entender que no es necesario superar la dualidad y así mantener la tesis de que los contrarios coexisten, alcanzando "una producción discursiva como un entramado complejo y múltiple” (2002, p. 100). Pero lo que Bocco no comprendió es que Kusch no se puede reducir al plano teórico o discursivo.

No se trata de manera exclusiva de teoría y marcos epistemológicos gracias a los cuales se posibilitan otras miradas y horizontes, para profundizar en ciertos conocimientos y disciplinas que hasta ahora se encuentran en cauces monológicos y unidimensionales, propios de la razón logocéntrica que viene desde los griegos. De hecho, la pretensión de Rodolfo Kusch es romper esos límites impuestos con los que de antemano nos encontramos colonizados, en particular los académicos. 
Por ello, el filósofo argentino trabaja para que, a partir de un ejercicio de comprensión que podría etiquetarse como existencial o vivencial, se posibilite no ver meramente, sino sentir el revés de la trama con que se nos presentan los discursos, los argumentos, las propuestas teóricas. Esas que nos conducen a entronar conceptos y categorías puras y trascendentales, bien justificadas desde lo racional y cuyo único sustento de fondo no es otro que la razón. Ejercicios racionales que se evaporan detrás de cada interpretación, según se van dando de forma histórica por uno y otro "pensador", en cada época, y que intenta hacer grande la historia que no es más que pequeña.

La gran historia, según Kusch, es la de quien se hunde en sus propias raíces y descubre su semilla, quien no le huye al hedor de los procesos concretos y vitales que ciertamente dan sentido a su existencia, así no se dé o no pueda ofrecerse un marco teórico ni una justificación epistemológica, como sucede con el indígena, con el campesino o con la señora que vende tinto en la esquina del barrio. ¡Así de concreta es la cuestión para este pensador!

Uno de los grandes develos de la práctica crítica actual es traslucir el discurso "hegemónico", dominante, legitimador. Entendemos que se trata de un trabajo importante que aporta un conocimiento necesario. Sin embargo, intuimos que comporta también riesgos: la simplificación de los textos y su reducción a un plano monológico en el que lo único que se escucha es el discurso hegemónico. Así, este se transforma en una especie de entelequia que obtura la emergencia de lo clandestino, lo periférico. (Bocco, 2002, p. 101)

Encontramos, entonces, en Andrea Bocco, un discurso crítico que va más allá del pensamiento hegemónico y colonial, y que viabiliza lo periférico, lo cual está muy bien. Sin embargo, desde el horizonte de Kusch, no es suficiente. En nuestro filósofo no basta cuestionar los fundamentos del pensamiento colonial que por su naturaleza es hegemónico, cuestionamiento que de por sí ya se enriquecería con una epistemología “de resistencia” que limitaría el discurso que obtura la 
emergencia de discursos de periferia, tan bien y diversamente argumentados en América Latina.

Lo clandestino y periférico no se reduce a lo que se niega en un discurso, ni al mero uso instrumental de la razón con sus productos lógico-matemáticos, ni a la justificación bien argumentada de "lo lógico y universal" con que se fundamenta la ciencia y el conocimiento a ese nivel, pues lo clandestino y periférico, en Rodolfo Kusch, es aquello que subyace tras todo discurso, el suelo desde el que se alimentan todos los discursos (no solo los hegemónicos), la geocultura que nutre toda reflexión, teoría y disertación racional, el hedor real y existencial desde donde se vivencia de manera "prelógica" todo sentir. De este último se alimentan los discursos y las teorías, los conceptos y las categorías epistemológicas, que engrandecemos en el ámbito académico aunque coartan la vida simple y sencilla, no solo la de los sencillos y los humildes sino la de académicos, investigadores y científicos. Ello es lo que hace perder el sentido vital, existencial, con el cual deberíamos vivir cada día, cada experiencia, cada suceso cotidiano.

De ninguna manera se quiere acá demeritar el nivel crítico de la lectura que adelanta Bocco sobre la obra de Kusch. Es en especial valiosa cuando habla de la comprensión de categorías que no puede quedarse dentro de la estantería de una biblioteca, sino que conlleva "su puesta en práctica en los estudios y análisis concretos, en su desenvolvimiento y tamizado por otras matrices teóricas" (2002, p. 101) y fundamentalmente, dice, por cofradías hegemónicas que acallan la polifonía de otras voces que también hablan. De todas maneras, como se ve, su crítica no va más allá del nivel discursivo, que es el nivel propio del pensamiento decolonial, cuyos aportes no dejan de enriquecer el mundo de la vida académica, pero que se quedan cortos a nivel del simple mundo de la vida.

Este hecho de la vida, o como lo llama Kusch, del puro vivir, del mero vivir allende los discursos vitalistas o antivitalistas, o neutros si se quiere, es el fundamento clandestino y periférico desde el que se va a fundamentar una ontología del estar. Por ello será, a su vez, una ontología existencial cuyo caldo de cultivo es justo este magma vital (no meramente teórico o epistemológico) que nutre de forma efectiva la apuesta ontológica de Rodolfo Kusch. La fagocitación no es, pues, un 
proceso conceptual o teórico con el que se asume de manera crítica la ciencia, el conocimiento o la cultura; la fagocitación es un proceso vital con el que se asume de manera crítica la existencia, de tal modo que sobrevivimos en medio de la polifonía cultural en la que nos encontramos siempre ya de antemano.

Conectado de forma profunda con el tema de la vida, está el del hedor, “dado que está muy relacionado con la respiración, un proceso que no puede suspenderse por mucho tiempo si se quiere continuar en este mundo" (Wajnerman, 2013, p. 64). Para el quincuagésimo aniversario de la publicación de América profunda, algunos autores fueron invitados a participar con reflexiones sobre "El hedor de América", un breve texto de Kusch que luego hizo de parte introductoria a la referida y homenajeada obra. Uno de los textos fue escrito por Carolina Wajnerman y es, tal vez, el que mejor evidencia la conexión entre vida y hedor. El hedor es clave para comprender el pensamiento de Kusch, y en este sentido vale citar el aparte de un poema ontológico presentado en las Jornadas Rodolfo Kusch de 2014:

No se sube de afán a la Am profunda, ni se desciende de afán, tampoco;

por más que el hedor nos impulse a dar pasos rápidos;

de nada sirve,

porque ahí mismo nos damos cuenta

de que no es un hedor objetivo,

sino de que es nuestro propio hedor.

Hedemos a América.

Para los no americanos, hedemos.

Hieden nuestras ciudades,

hieden nuestros edificios;

hiede nuestra política,

hiede nuestra cultura;

hiede nuestro tiempo,

... ¡hiede la Eternidad! 
¿Y qué ser vivo no hiede?,

¿qué ser humano no hiede?

Mírate las tripas.

Cuando sabemos sentir desde las entrañas nuestra existencia:

¡hedemos!

Estamos: hediendo.

Somos: hediendo. (Cepeda, 2014)

Y es que somos hedor porque somos vida, no cabe duda de ello. La apuesta de Rodolfo Kusch no fue ajena a esta realidad. Wajnerman señala cómo la glándula sensorial del olfato está justo en el centro del cerebro, en el sistema límbico, y así, "a través de un aroma, podemos acceder directamente a las emociones" $(2013$, p. 64) o a procesos de la memoria. Sin embargo, nuestra cultura no se centra en el olfato, y por ello nuestro lenguaje da cuenta con mayor frecuencia de palabras referidas a otros sentidos. Incluso para referirnos a algunos olores lo hacemos a través del sentido de la visión o del oído, como cuando se dice que huele a chivo.

Faltan estudios profundos sobre el sentido del olfato que nos permitan comprender los aromas de ciertas partes del cuerpo, o aquellos propios de los alimentos o la morada. Wajnerman también llama la atención sobre el hecho de que los seres humanos buscamos oler diferente a nuestro propio olor, y por ello la búsqueda de fragancias que posibiliten estas costumbres culturales: aromatizantes, desodorantes, perfumes. Con ello se quiere, en el fondo, negar el hedor. Rodolfo Kusch no se propone negarlo sino asumirlo, lo integra en vez de excluirlo, "pues en el hedor está la ira de Dios y también el miedo al azar de la vida" (Wajnerman, 2013, p. 66). Lo que olemos no es solo invisible y bastante difícil de expresar, sino que nos ofrece una conexión directa con nuestras emociones, las que nos posibilitan la mística y un sentido profundo de la vida, además de acceder a saberes también profundos: poder sentirnos parte de la naturaleza con este cuerpo que experimenta de manera emocional.

Unos y otros hedemos, como lo expresa el aparte del poema citado; "el otro es otro con su olor, y yo y mi propio olor soy el uno" 
(Wajnerman, 2013, p. 68). De todas maneras, siempre, el olor desde el cual se "miden" los demás es el de uno, sin que uno mismo se dé cuenta. Sin embargo, "el hedor kuschiano se remite específicamente a la h(edi)onda América, por lo que la diferencia que se percibe olfativamente respecto del otro nos lleva a pensar en el problema de la interculturalidad" (Wajnerman, 2013, p. 68). Vida-hedor-interculturalidad, ¡hay que pensarlo! A los otros puede no gustarles el olor de uno, y a uno puede disgustarle el olor de otro. Así que oler al otro implica y exige a su vez olerse a uno mismo.

El olerse un poco en los vínculos puede leerse entonces en dos sentidos: puede ser el olerse entre dos o más y también un olerse a sí mismo. Quizás desde allí podrá establecerse, desde mis propios olores, un vínculo posible con los aromas del otro. Además, por esta vía, puede cuestionarse la ontología occidental basada en la visión de individuos, donde la alteridad es una amenaza para el sí mismo, por lo que se busca reducir al otro. Por otra parte, también solemos reducirnos a nosotros mismos, por ejemplo, en términos de olor. (Wajnerman, 2013, p. 69)

Oler, por lo general, significa oler al otro u oler lo otro, porque lo usual es no sentir el propio olor. Oler al otro puede significar olfatear al otro o a lo otro y marcar la diferencia: no importa quiénes somos (cómo olemos), pero sí que nos importa quiénes (no) son los otros, cómo huelen, e inclusive de forma explícita: cómo hieden. Y en cuanto el hedor se convierte en una amenaza, también resultamos - de una u otra forma- amenazando al otro. Pero oler al otro, además de significar olfatear al otro, como lo señala Wajnerman, también significa oler uno mismo a lo que huele el otro: yo huelo al otro, entonces quiere decir, o que yo olfateo el olor del otro, o que yo huelo a lo que huele el otro, mi olor es el mismo del otro: oler al otro.

En la pasantía de investigación doctoral realizada en los archivos personales y en la Biblioteca de Rodolfo Kusch, en Maimará (Argentina), también se realizaron algunas salidas de campo para conocer in situ el noroeste argentino donde Kusch, decenios atrás, realizó 
su trabajo de campo. Una mañana, al tomar un remix para visitar una vereda cercana a Tilcara, también se subió una señora de campo con su traje típico, el de la región, similar al de las bolivianas, con sus varias y anchas faldas, su pañolón y sombrero característicos. Cuando la señora se bajó a mitad de camino, el conductor nos miró a todos y haciendo un gesto con el que criticó el olor de la señora, abrió por completo su ventana, a pesar de ir por un camino destapado. Ninguno de los que usábamos el servicio del remix dijo una sola palabra. $\mathrm{Ni}$ siquiera el conductor.

¿Solo porque ninguno dijo nada, el conductor tampoco dijo nada?, ¿acaso ninguno debía decir nada?, ¿todos comprendimos, al final, que la señora, por ser del campo, no tenía otra posibilidad que oler a campo: a cabra, a vaca, a abono, a tierra?, ¿no es gracias a esa señora que madruga a ordeñar las vacas y ayuda a su marido a aporcar el sembrado, a cocinar en el fogón, que duerme con toda su familia a veces en una misma cama, no es gracias a esa mujer — preguntamos- que nosotros nos alimentamos mejor y no tenemos que ir a ordeñar, a aporcar o a cocinar con leña?

Cuando los borrachos están entre borrachos ninguno siente el hedor del otro, y así sucede cuando los campesinos están entre campesinos. Oler al otro, también es oler a otro: mi olor también es el olor del que permanece conmigo, nuestros olores se juntan, y uno termina acostumbrándose o a la fragancia o al hedor del otro. Todos hedemos: estamos hediendo, somos hediendo. La vida, toda, hiede, desde la semilla, y sobre todo cuando esta germina. Hay que estar en los semilleros, donde se guarda y cuida la semilla en el campo, en especial la de los tubérculos como la papa. Hiede la vida, así es. El hedor es universal. Pero lo venimos a afirmar desde el hedor nuestro, con el que hemos sido negados por centurias por aquellos que hedían más que nosotros.

¿Quiénes eran los hedientos, entre los conquistadores de América y sus habitantes? Recordemos que, en la Europa de esos tiempos, no era para nada habitual bañarse; fue por ello que allí se encuentra la cuna de los perfumes artificiales. Entre los habitantes de nuestras tierras, tomar baño era un hábito diario. Aun así, 
el salvajismo y la falta de humanidad fueron puestos del lado de los pobladores de América y los descendientes de estos tuvieron que soportar los despojos de una conquista bastante maloliente. (Wajnerman, 2013, pp. 67-68)

Cuando sabemos sentir nuestra existencia, desde las entrañas, hedemos. "Habrá que tener en cuenta el olfato de todos, así como la integración de sentidos para la construcción del camino que, ya lo dijo el poeta, se hace en el mismo andar" (Wajnerman, 2013, p. 69). En el camino a la pulcritud nos topamos con próceres heroicos, con políticas teóricas, con economías impecables, con educación intachable, propias de las republiquetas prósperas de América Latina, según apunta Rodolfo Kusch. Quien se considera pulcro ha olvidado olerse a sí mismo y no sabe comprender que parte de su olor es el de los otros; de ahí los anatemas, las inquisiciones, los procedimientos objetivos de investigación, etcétera.

Sentir al otro implica olerlo y olerse. "Conectarnos con nuestro olfato y preguntarnos por el sentido que otorgamos a lo que olemos necesariamente modificará nuestros modos de estar y ser" (Wajnerman, 2013, p. 70), en especial si se busca comprender estos modos incluyendo lo intuitivo y lo emocional, lo lírico y sentimental, por ejemplo. "Ello requiere nuevas formas de percepción y vinculación, no solo respecto a la realidad construida socialmente sino también con nosotros mismos" (Wajnerman, 2013, p. 70), lo que exige también nuevos horizontes de comprensión que posibiliten aproximarnos a esas realidades desde cánones diversos al "único", tomado como cierto y creído como verdadero, aquel propio del paradigma de la razón objetiva, lógica y científica, desde el que Occidente se ha impuesto y desde el cual lo otro "huele mal".

En la filosofía de Kusch, vida y hedor van a una. “¿Cómo estar con el otro si no puedo compartir el acto de respirar el mismo aire u otros aspectos similares de la vida cotidiana?” (Wajnerman, 2013, p. 72), o simplemente, ¿cómo estar? Estar oliendo es una de las sensaciones de estar vivos. "Negar" el hedor con que hemos sido negados nos posibilita "estar", nos afirma en nuestro estar-en-el-mundo, aunque este sea un mundo en caos que busca su equilibrio. "[...] por suerte, por el 
lado de las ciencias mal llamadas duras y exactas, ya se viene diciendo que el caos es simplemente un orden cuya lógica aún no logramos comprender y por eso confundimos caos con des-orden" (Wajnerman, 2013, p. 74), aunque a veces pareciera que son más duras las llamadas ciencias blandas, o ciencias sociales y humanas, que aferradas al paradigma de la razón silogística con su lógica "objetiva" no se permiten la humanidad de lo emocional, de lo sensible y sentimental, y por ello no pueden aceptar cómo la ontología habla por medio de la poesía o cómo una investigación ontológica pudiera presentarse en un poema ${ }^{2}$.

¿Qué papel desempeña la vida en la comprensión ontológica de Rodolfo Kusch? Para finalizar este apartado deberá señalarse cómo en una ontología, interesada en el problema clásico del ser, se hace necesario y fundamental ahondar en el problema de la vida. Y lo primero que hay que hacer es ratificar que en Kusch la ontología no es un problema teórico, ni solo racional o abstracto. La ontología, que de manera universal se pregunta por el ser en cuanto tal, se levanta sobre el sustrato fundamental de toda nuestra existencia: la vida.

El hecho de vivir es la raíz sobre la que se levanta el tronco de todas nuestras posibilidades, y en semejante tronco se sostendrán, luego, los diversos saberes en los cuales se realiza la existencia concreta de cada ser. La única manera en que lo americano, el ser humano, la sociedad, la ontología, la realidad toda cobran sentido es desde una comprensión vital. Y como se observó, Kusch asume la vida desde aquel fondo seminal donde el hedor cobra importancia, también fundamental. No se trata de la vida como una categoría biológica ni ontológica, no se

2 Se encuentran muy pocas excepciones. Indudablemente, se continúa considerando digno de estudio "objetivo" el poema de Parménides, un texto fundacional de los estudios sobre el problema del ser; como se vio, Heidegger supo argumentar cómo el poeta es quien mejor revela el ser y él mismo, en sus últimas obras, nos ha presentado algunos textos en poema; además, se encuentran, aunque pocas, revistas académicas que publican avances de investigación en verso, por ejemplo, Cuadernos de políticas culturales. Indicadores culturales 2014, que publicó mi texto: "Sentipensar ontológico. Un atisbo latinoamericano de la respuesta a la pregunta por el ser, bajo el horizonte kuscheano del filosofar". 
trata de llevarla a su nivel conceptual y abstracto donde se argumentaría, como es debido, de forma pulcramente racional.

Lo que Kusch busca es hundirse en la experiencia profunda de la vida, hasta su nivel seminal, donde germinan todas las posibilidades existenciales que permiten que, en efecto, se dé el estar. Vale insistir que no se trata de conceptualizar la vida, lo que se busca es sentipensarla (aunque Kusch no conociera este término), adentrarse en su experiencia, vivenciarla desde su fondo más “oscuro" y lóbrego, en el que hieden sus mejores posibilidades.

El interés por lo pulcro, conceptual y lógico-racional, propio de las investigaciones objetivas, desarrolladas desde el ámbito científico, no constituyen el propósito del ejercicio realizado por Rodolfo Kusch. Habría que indicar, más bien, que lo seminal y su fruto, la vida y su ímpetu orgánico, la vivencia en cuanto existencial que se aferra y nutre lo sentiente era lo que en realidad le interesaba al filósofo argentino. Esto fue lo que descubrió hundiéndose en el magma bárbaro de lo latinoamericano, en su paisaje agreste y salvaje, en sus tradiciones ancestrales y mágicas, en sus sabidurías cósmicas y sagradas, en lo profundo del pensamiento indígena y popular.

Y "lo seminal, esto que crece y no sabemos por qué, tiene que ver con el estar y con el pacha andino, donde Kusch justamente indagó la América Profunda” (Cullen, 2015, p. 71), porque si la negación se da en el orden de la vida, también esta, en su comprensión seminal y hedionda, nos conduce e implanta en el estar, asunto fundamental para la ontología que se piensa desde América Latina.

\section{Estar, fundamento "total” de lo que es}

Es indudable que el estar es la categoría fundamental del pensamiento de Rodolfo Kusch. Ya quedó evidenciado cómo esta se va constituyendo a través de sus investigaciones. En 1996, Gabriel Osvaldo Sada hizo una aproximación a este concepto a través de las obras de Kusch. Como es natural, comienza con La seducción de la barbarie, en donde contextualiza que esa idea de peso del paisaje en América Latina seguramente la trae de Martínez Estrada e inclusive de Lévi-Strauss. 
Señala Sada, cómo aún no aparece el estar, pero en cambio sí aparece el ser "ligado a las ideas de razón y ciudad que se opone a lo irracional en lo cual entran sin embargo en mayor proporción los valores vitales" (1996, p. 86). Es algo así como un desdibujarse de lo que de manera tradicional comprendemos como ser, sin saber hacia dónde se deba orientar dicho concepto, ahora a la intemperie, porque estar, en 1953, aún no ha sido vislumbrado en el horizonte de Kusch, según Sada.

Dos años después de la publicación de La seducción de la barbarie, en un texto sobre estética latinoamericana, Kusch volvió a indagar sobre el contexto geográfico, gracias al cual se devela la experiencia indígena, desde la conquista, como un proceso de refugio que va de la llanura a la meseta; mientras que el conquistador llegaba con una actitud contraria, alimentada por las culturas eurasiáticas, con experiencias que iban de la meseta a la llanura, mediante elementos dinámicos, como el caballo y la rueda. Sada aclara que estos términos solo le sirven a Kusch para oponer el orden de una actitud del europeo con el del latinoamericano, ya que, por sí mismos, no resisten una fundamentación histórica que, además, desde lo conceptual, podrían usarse al contrario, como lo hiciera, por ejemplo, Canal Feijóo. Lo que sí debe resaltarse acá, de manera atinada, es que dichos conceptos serán los que en textos posteriores se identifiquen con ser y estar, respectivamente. Sea la oportunidad acá para señalar que entre 1956 y 1960 , Rodolfo Kusch escribe algunas obras de teatro, en las cuales, sin embargo, los conceptos de ser y estar casi no aparecen, y menos con el sentido que luego les dará.

Será, entonces, en 1963, con la publicación de América profun$d a$ que se expliciten los mentados conceptos ya en el horizonte que va abriendo la comprensión kuschiana. Sada expresa que, ya en el exordio del libro, Kusch intuye que lo americano, en el sentido de lo latinoamericano, oscila entre dos polos: el de ser o ser alguien y el de estar o estar aquí, lo que permite entreverlos como categorías culturales con cierta tendencia ontológica. Mientras el ser (ser-alguien) corresponde a la mentalidad europea, el estar (estar-aquí) corresponde a la mentalidad indígena, y la tensión entre los dos pertenece al mestizo. Según Kusch, el quechua da cuenta de esta mentalidad indígena, por lo que gramaticalmente quedaría sustentado; pero, además, por la estructura 
social de las comunidades indígenas en su ayllu, en el que se evidencia un estar-aquí aferrado a la tierra y a sus gentes.

Hay que tener en cuenta que, a este nivel, el estar no funge como un concepto filosófico, dice Sada; asunto que el mismo Kusch tiene bastante claro cuando expresa que darle ese doble sentido al estar no es más que una herejía filosófica. Sin embargo, el filósofo argentino aduce de inmediato que el estar no es una categoría tan diferente del Dasein heideggeriano y que, además, él mismo lo usa para romper la continuidad con el concepto de ser.

Entendemos ahora por qué es una "herejía filosófica", a saber, porque la búsqueda de un sentido de lo real a través del mundo indígena está acompañado de la voluntad de contestar otra ontología: la ontología del ser. De ahí que Kusch compare la postulación del estar con la tarea de Duns Scoto al plantear su concepto de hecceidad como nuevo elemento en la ontología medieval. (Sada, 1996, p. 94)

El uso del término ser, en Kusch, está definido por aquella forma en que lo entiende Ortega y Gasset: verbo activo, de ejecución, de ejercicio, como "el esforzado sostenerse de algo en la existencia", según citan a Ortega, primero Kusch y luego Sada. De allí que este último se pregunte si acaso la de Kusch no sería una filosofía de la existencia, es decir, si estar se corresponde a existencia, como ser a esencia.

En el segundo libro de América profunda estar se liga al puro vivir, y por consiguiente se "universaliza" su significado al asignarlo como propio no solo de los latinoamericanos (o americanos) sino de todos los seres humanos, e inclusive de todos los seres vivos. Así, ser y estar encarnan dos experiencias que posibilitan dos ritmos no idénticos de la vida y la cultura: mientras el ser se relaciona con el mundo intelectual y con la preeminencia del individuo, el estar se relaciona "con lo vital, la acomodación al ámbito, la preeminencia de lo comunitario" (Sada, 1996, p. 97).

Para Kusch el estar es fundamento del ser, según Sada, por tres razones: la primera es la histórico-cultural, según se ha visto por la historia y la cultura en Europa y Latinoamérica; la segunda es la energética 
o biológica, por la fuerza vital que encierra el estar; y la tercera es la genealógica, ya que además de que el ser emerge del estar también a él volverá, por el hecho de la fagocitación (Sada, 1996, pp. 99-100). Con ellas, considera Sada, ya Kusch gana el concepto buscado en $\mathrm{La}$ seducción de la barbarie, al que solo le quedará explicitarse en los diversos contextos de sus siguientes obras, a saber, el contexto americano, la identidad de los pueblos y las comunidades latinoamericanas, y la filosofía contextualizada que se hace nuestra, en particular para la fundación de una ontología latinoamericana (Sada, 1996, p. 102).

De las dos obras de 1966, De la mala vida porteña e Indios, porteños y dioses, constituidas por conferencias radiales, Sada presenta seis anotaciones con respecto al concepto de estar. Primera: estar es dejarse-estar, como lo vivencia el indígena o como lo expresa el tango. Segunda: el estar indica cierta accidentalidad, con respecto a ser. Tercera: también significa la mera vida, la pura vida, el puro hecho de vivir. Cuarta: indica un movimiento que incluye la negación. Quinta: estar es la presencia indiscutible de lo que se da ahí y pa' mí. Sexta: incluye los opuestos, en particular comprendido como un estar cósmico (1996, pp. 103-106). A estas se añadiría la función política del estar: "El estar es entonces un concepto que busca desmontar un discurso 'crispado', propio del hombre americano occidentalizado" (Sada, 1996, p. 107).

De igual manera, el estar también se sustenta desde el pensamiento indígena, como sucede en El pensamiento indígena y popular en América, de 1970. Para Sada, acá el concepto de estar tiene dos formas: una "presente" en el indígena y en el pardo, y una "ausente" en el blanco, aunque también en el indígena cuando padece procesos de aculturación (1996, p. 108).

En la obra de Kusch que acabamos de mencionar también hay un uso de conceptos que Sada se detiene a explicar: aunque en América profunda el estar se asemeja al Dasein, ahora toma una distancia bastante mayor. Kusch aduce que estar corresponde más bien al término utcatha, en aimara. Recuérdese que en aquella obra la intención era darle un "nivel filosófico" a la discusión, mientras que en El pensamiento indígena y popular en América lo que se quiere es radicalizar el pensamiento indígena en cuanto tal: "El estar (utcatha) relaciona 
el ser del hombre americano con las ideas de amparo y germinación" (Sada, 1996, pp. 111-112), como sentir profundo del indígena, dentro de su experiencia cosmológica, y de ninguna manera se relaciona con una "caída" de algún Dasein.

Además, se anota cómo hay una aparente contradicción etimológica si se tiene presente que estar, del latín stare, significa 'estar en pie', mientras que en aimara, utcatha, significa estar sentado. Es el mismo Sada quien aclara, buscando evidenciar la intuición de Kusch alrededor del concepto de estar, un sentido de cierto "estatismo", pero dinámico en el interior. Ya observábamos en el capítulo anterior de esta investigación, también, cómo el estar se relaciona con pacha y así.

Otro estudio sobre el estar se encuentra en el capítulo "Estar y ser en la ontología americana”, del libro Ontología a la intemperie. Kusch: ontología desde América de Nerva Bordas de Rojas Paz, que inicia diciendo sin titubeo alguno que: "El momento fecundo de la especulación de Kusch tiene lugar cuando dirige su discurso a la fundamentación de una ontología desde América” (Bordas, 1997, p. 47).

La distinción entre estar y ser se da, según Bordas, cuando se quieren distinguir dos ámbitos de significación a la hora de aprehender la realidad: "Por un lado se da la existencia de lo preconceptual, donde, previo a definir, se plantea la pregunta por el sentido. Es el ámbito del estar" (Bordas, 1997, p. 49). El ámbito del ser, por su parte, privilegia el conocimiento de las cosas, y con ello las definiciones y los conceptos. Estar, de stare, traduce la inquietud donde, al no definirse, rige lo innombrable, la dimensión sagrada. El ser se fija en la definición, en los conceptos, y supone captar, así, lo que es. Entre los dos emerge una tensión, la tensión propia del latinoamericano que no quiere imitar lo extranjero y en cambio está a la búsqueda de lo propio, "encerrado en un pensamiento que no lo potencia porque no logra captar aquello que define su ontología” (Bordas, 1997, p. 49).

Lo que Kusch encuentra en el estar es esa peculiaridad latinoamericana que habrá de darnos nuestro verdadero lugar "y no esa penosa universalidad que todos pretendemos esgrimir inútilmente" (Kusch citado por Bordas, 1997, p. 50). Nerva Bordas también señala la distancia entre el pensamiento culto que se enseña en la universidad y el pensamiento popular que se vive en "lo privado", en la calle o en el 
campo, según lo expresa Kusch en De la mala vida porteña. Mientras más se es, menos se está, o mientras más se está, menos se es, porque lo uno intenta negar lo otro.

Kusch presenta el estar "como ámbito que concentra la originalidad de un vivir no sometido a racionalización previa sino sumergido en la dimensión fundante de lo que está dado como tal" (Bordas, 1997, p. 51), desde donde se nutre la creación simbólica y, por tanto, cultural. Por esto mismo el estar exige un ámbito de comprensión diferente al del ser, que sería, además, por completo incomprensible, si la aproximación se hace desde semejante horizonte, y que trae como consecuencia la separación de la ontología latinoamericana de esa verdad que busca darse.

Por ejemplo, es factible decir que en el estar no hay progreso: la afirmación puede ser cierta pero desajustada. Podría no tratarse de una carencia, sino de una riqueza. En su valoración del mundo no le interesa "el progreso" occidental, sino el "crecimiento" que acompaña el ritmo cósmico del mundo diseñado por los dioses. (Bordas, 1997, p. 52)

Por ello la ontología latinoamericana no puede recurrir de manera tan fácil a categorías extrañas, pues con ello no nos "hundimos" en la riqueza propia y, por otro lado, perdemos el sentido de lo propio. En cambio, si lo que buscamos es el sentido del ser, no debemos abandonarlo, solo que será necesario aproximarnos a él desde el estar, el cual nos ofrecerá nuestro concepto "auténtico" del ser. La totalidad de lo óntico (el ente) o la esencialidad del ser (que se define y categoriza) no pertenecen al ámbito del estar. Este constituye un paso previo, como "cuando Viracocha va siendo el mundo".

El estar se da antes de la investigación de las esencias, sin que "estas resulten negadas, sino que se trata de establecer prioridades ontológicas: ese nivel preóntico apunta al sentido antes que al ser" (Bordas, 1997, p. 53). Recordemos que Kusch llama al estar "prerrecinto del ser", instalado — de alguna manera- en la voluntad divina, es decir, en lo sagrado, “cuando Viracocha va siendo el mundo”. Acá, 
sin duda, se encuentra cierta relación con el Ereignis de Heidegger, pero no hay que olvidar que es justo el filósofo alemán quien desliga su ontología de toda ontoteología, lo que ya evita cualquier similitud con la apuesta de Kusch, no porque el pensador argentino buscara fundar una ontoteología, sino porque una ontología del estar jamás podrá comprenderse desde una racionalidad que asume el devenir de una manera tan aséptica como lo hace Heidegger y desde la cual comprende el ser.

Se podría decir que acontece el estar, como lo sugiere Nerva Bordas, pero siempre teniendo en cuenta la anterior aclaración. Al fin y al cabo, al ser le es propia la causalidad mientras al estar le pertenece la seminalidad, y esto ya sienta la diferencia entre las dos concepciones. Estar: seminalidad y crecimiento, hasta dar fruto; por ello la importancia del suelo como fundamento (de lo que está y de lo que es) que posibilita un modo de vivir (geocultura).

Nerva Bordas recuerda cómo en Geocultura del hombre americano, la verdadera dimensión del estar se da a nivel del miedo. "Para caracterizar el estar, Kusch introduce la dimensión ontológica del miedo" (1997, p. 56); el miedo es un dato ontológico trascendente: una carga que arrastra el ser humano cuando la vida abre sus puertas a lo sagrado. Ya en América profunda se había mostrado cómo, desde el paradigma racional lógico-matemático, se desalojan los miedos al patio de los objetos y se va tomando distancia de lo sagrado. Desde la experiencia popular y ancestral, que constituye el paradigma de la vida simple y sencilla, se mantiene el miedo natural propio de lo mágico, lo sagrado y lo místico, que acompaña al pensamiento seminal, sea en el campo o en la ciudad. Ser y seguridad, sobre el mundo con la ciencia; estar y miedo, en el mundo con la naturaleza.

Cuando la filosofía occidental abre la pregunta por el ser, aparece su opuesto: la nada. Según nuestro autor, esa nada no es sino el estar como potencialidad de todo, una nada llena. La identificación hegeliana entre el ser y la nada representa el momento del ser en su máxima indeterminabilidad. Es también la indeterminación óntica que vive el estar. Esta relación que hace Kusch puede tener que ver con la pérdida del estar europeo; no estaría lejos 
Hegel de querer recuperarlo aunque en otro contexto y con otra comprensión de lo sagrado. (Bordas, 1997, p. 57)

Con el miedo, se comprende mejor el estar desde la emocionalidad y como unidad biológica que incluye casa, paisaje, trabajo, ciudad; se identifica más con el sentir que con el ver, y supone una indigencia que obliga a confiar en lo sagrado. No es exclusivo del indígena o de quienes tienen contacto con lo ancestral -Europa lo perdió en la modernidad-, es parte de todo ser humano y de toda la realidad. En 1989 se publicó una antología, Kusch y el pensar desde América, donde Nerva Bordas profundiza en el miedo kuschiano. El contexto que propone es el de la vida académica y los proyectos de investigación que se sustentan con preguntas ya formuladas por Europa, por lo general, desde donde ya vienen delineadas las respuestas.

La intención de Rodolfo Kusch sería, entonces, reformular una de esas preguntas desde lo propio, cuestionando la tradición de la enseñanza, el significado de la universidad y el rol que desempeña. Pensar la pregunta "nos obliga a partir de un mundo de tinieblas, iniciar un camino nuevo casi con las manos vacías y toparnos, de pronto, con el miedo original de ser desde un estar" (Bordas, 1989, p. 103). Ese ha sido el trabajo de Rodolfo Kusch: liderar tal camino, podría decirse, desde sus más desérticos inicios, tarea nada fácil, pues debió hundir el arado en un terreno algo seco para abrir surcos profundos en el campo de la ontología y, como se sabe, hasta ahora nuestras investigaciones normalmente solo echan mano de fuentes extranjeras o nacionales con métodos extranjeros.

Acá radica la importancia de pensar una ontología latinoamericana, nuestra, profunda, que emerja desde nuestros miedos y en el horizonte de nuestras culturas, como lo ha hecho Rodolfo Kusch. "Podrá o no ser compartida su metodología o pensamiento, pero no podrá negarse la coherencia y la importancia de lo que se propone, así como el vacío que viene a cubrir en el ámbito filosófico universitario" (Bordas, 1989, p. 105). Se ha esforzado por pensar en armonía con su medio, asumiendo la repulsa que ofrece nuestro propio suelo, enriqueciendo los conocimientos con saberes seminales y rescatando ese pasado ancestral que nos corresponde, inclusive, en zonas donde 
aparentemente ya no queda, como puede ser Buenos Aires o Bogotá. Kusch mantiene siempre su compromiso con la tierra y argumenta con ahínco, por ello mismo, una geocultura desde la cual se nutre el estar (Bordas, 1989, pp. 105-107).

¿Dónde se radicaliza el estar, para concentrar allí la investigación? En el pensamiento indígena y popular. ¿Y se puede continuar haciendo filosofía, sin más, si se quiere hallar y fundamentar ese pensamiento propio que, en definitiva, no se identifica tal cual con la filosofía europea? Faltan los instrumentos necesarios para proyectos de investigación nuestros, de lo propio, que aprecien nuestras culturas y saberes: "Es entonces cuando aparece la dimensión del miedo, de un miedo original que necesita ser resuelto de manera coherente con la solución que lleva a cabo la comunidad cultural” (Bordas, 1989, p. 109).

Kusch encuentra las raíces del miedo en la ira divina que expone Pachacuti en su manuscrito. Y parecería que el miedo no se ha quedado con nosotros, pues debido a la ciencia con sus tecnologías, por alguna razón, hoy día ya no tendríamos que tener miedo. Sin embargo, no es así. Los criollos, los mestizos, sobre todo nosotros, damos cuenta de esos miedos que continúan vigentes, que hacen parte de la naturaleza del ser humano:

Kusch afirma que lo propio de Europa es un saber de las cosas para afuera; privilegia el mundo exterior donde concentra sus esfuerzos cognoscitivos. Ese mundo es lo dominable y esa función de dominio permite que los miedos sean desalojados, y con ellos los dioses, los mitos, el misterio, lo indomable. Sin miedos, el hombre en abstracto se propone dar cuenta del mundo. El indígena, en cambio, no hace la experiencia de un mundo vacío de dioses y por tanto dominable; el mundo es un espacio a compartir con dioses y demonios que le exige saber en profundidad, de la piel para adentro. (Bordas, 1989, p. 110)

En estas tierras, considera Bordas, los miedos siguen a flor de piel. Al regresar de la empresa, en las noches, nos encontramos de nuevo con nuestros miedos. Subyace la vivencia del indígena con su sabiduría 
que privilegia un saber de la vida antes que un conocimiento de las cosas, inclusive en la empresa misma. Aunque la tecnología y los medios de información nos impongan vivir sin dioses, los miedos siguen presionando en la realidad " $\mathrm{y}$ — dice Kusch— aunque entre los dioses y el miedo pongamos las cosas y la diosa razón, lo real es que se sigue teniendo miedo a que no llueva" (Bordas, 1989, p. 112).

Con el miedo se comprende mejor el estar, insiste Nerva Bordas, según lo anunció Kusch en Geocultura del hombre americano: la verdadera dimensión del estar debe entenderse a nivel del miedo. En el miedo original todos los pueblos revelan cómo han afrontado su organización del mundo y la vinculación con lo sagrado, y su tratamiento tiene carácter cultural. Entre las culturas ancestrales el miedo ofrece una medida del ritmo biológico, o sea que es directamente proporcional a la experiencia de la vida (y de la muerte), sin afán y sin angustia. Al fin y al cabo, la angustia es un miedo disfrazado, solapado, y ya desde Kierkegaard hasta Heidegger se ha estudiado el papel de la angustia en la cultura occidental.

En el pensamiento indígena y popular, el miedo se conjura, en búsqueda de restablecer el equilibrio natural. Así, “desde la vivencia universal del miedo ontológico se alcanzan soluciones culturales que ponen de relieve un carácter particular" (Bordas, 1989, p. 115). Occidente ha buscado dominarlos para disolverlos, pero los miedos siempre reaparecen y se instalan, por ejemplo, en las preguntas con que buscamos sentido. Otras culturas no han querido disolverlos ni negarlos, sino asumirlos, y los conjuran: con un grito, con una danza, con un sacrificio... o, diríamos acá, con una apuesta filosófica que no los anule sino que los contenga de forma armónica, y que por ello mismo hable de estos y, además, del hedor, del resentimiento, la negación y el estar:

La filosofía latinoamericana descubrió así que tanto la pregunta por el ser como el cuestionamiento ético-histórico que la reubi$\mathrm{ca}$, la libera y le da la posibilidad de hacerse efectiva, suponen un momento previo a ambos [...], podemos denominarlo - siguiendo el camino señalado por el eminente pensador R. Kusch—: ámbito del "estar" (estar-en-la-tierra), para diferenciarlo tanto del ámbito especulativo del ser como del ámbito ético del bien (y 
del acontecer ético-histórico), y a la vez relacionarlo con ambos. (Scannone, 1989, p. 74)

De lo anterior se infiere que con el estar no solo se le apuesta a una ontología que resulta ser "nuestra" — cuya estructura conceptual se ha venido mostrando en esta investigación-, sino que se le ofrece consistencia a la tarea "mayor" de la filosofía latinoamericana. Además, Scannone también explicita que entre la pregunta por el ser (como herencia de la filosofía griega) y el horizonte del acontecer ético-histórico (como herencia de la tradición judeocristiana), comprendidos desde el estar (propio de la sabiduría indígena y popular), se da una circumincesión intercultural del pensamiento que en América Latina se presenta geoculturalmente situada en función de la vida (Fornet-Betancourt, 2001, pp. 13-14).

En síntesis, ¿qué se debe apuntar como conclusión de este apartado acerca del estar? En los casos anteriores se ha concluido de manera argumentativa, como es tradición en la filosofía occidental. Sin embargo, justo cuando nos aproximamos al sentido del estar, ¿puede continuar argumentándose (teóricamente) desde la misma racionalidad que ha llevado a la crisis de la metafísica (Lértora, 2001, pp. 27-29), debido a que ha olvidado el sentido de (su) ser? ¿No se tendría que seguir también el ejemplo de nuestras culturas ancestrales e intentar concluir de otra manera?

Podría ser de manera poética, según lo indicado por Martin Heidegger y señalado, además, por Leopoldo Marechal (Maturo, 2004, pp. 57-69). O tal vez mejor con una metáfora, de esas que abundan en los relatos latinoamericanos, africanos y orientales, donde aún mantienen su sentido profundo y existencial. Sí, concluyamos, mejor, con una "historia" de Carl Jung, de Los complejos y el inconsciente, citada por Abraham Haber (1989) y que de seguro conocía muy bien Rodolfo Kusch:

Una gran sequía desolaba la región de Kiautschau y los habitantes estaban desesperados. Los católicos hicieron procesiones expiatorias, los protestantes, por su parte, elevaron el domingo sus rogativas para la lluvia; y los chinos, en fin, no vacilaron en 
ofrendar unos juegos artificiales. Pero todo fue en vano; el Consejo Provincial decidió entonces llamar a un experto, "hacedor de lluvias" de una provincia del interior, de Shantung. Este respondió a la invitación. Le fueron a recibir a las puertas de la ciudad, donde le preguntaron: "Maestro, ¿qué podemos hacer por ti? ¿Qué deseas?". Respondió: "Procuradme, fuera de la ciudad, una casita, rodeada de un pequeño jardín”, y en ella estuvo encerrado durante tres días. A la mañana del cuarto día cayó nieve a grandes copos, lo que, en aquella estación, superaba las esperanzas de los más optimistas. El entusiasmo fue grande y la multitud gritaba por las calles: “iEs el hacedor de lluvia!”. Richard Wilhem, que estaba de paso por la ciudad, fue a visitar a este hombre y le preguntó si le quería explicar cómo había logrado la lluvia. El chino le respondió con cortesía:

—No la he logrado yo.

—¿Por qué te llaman entonces el "hacedor de lluvia"?

— ¡Oh! Puedo decírtelo, es muy sencillo: yo vengo de Shantung donde llovía normalmente, como debe llover, y donde todo estaba en orden; por consiguiente yo también estaba en orden. Pero yo vengo a Kiautschau donde reina la sequía, cosa que no está dentro del orden, lo que hace que esta tierra no esté en orden, y que yo, que llego a ella, no esté tampoco en el orden. Por eso necesito una casita donde pueda estar tranquilo, donde me pueda hundir en el Tao. Durante tres días y tres noches he trabajado sobre mí mismo, hasta que al fin he vuelto a alcanzar el Tao; entonces, naturalmente, una vez restablecido el Tao, ha empezado a llover. (Jung citado por Haber, 1989, pp. 46-47)

\section{Negación-vida-estar: estar-siendo}

Como ya se expuso, el pensamiento indígena y popular busca el equilibro natural, una armonía sin extremos ni polarizaciones. El estar radicalizado podría entenderse como el polo opuesto al ser, que buscaría entonces imponerse y colonizar toda la filosofía occidental. Esto lo 
comprendió con toda claridad Rodolfo Kusch. Sabemos que "ambos extremos son necesarios, para afirmar la totalidad de la existencia" (Cullen, 2015, p. 70) y la totalidad de lo real. ¿Podría comprenderse una ontología íntegra sin darse, en su apuesta, un "diálogo" intercultural?

La filosofía intercultural es, entonces, uno de los presupuestos de la ontología cuando lo que pretende es una comprensión de lo que es, del ser en sus más abstractas conceptualizaciones como categoría formal y universal. El ser entonces busca y señala su esencia, a la vez que está enraizado en el suelo que lo nutre y lo comprende de manera vital; aun a costa de negar esa abstracción esencial, para dar paso a su estancia interior sin la cual no podría darse como tal. "Entonces, ser y estar: estar siendo. Ese movimiento pendular entre el ser y el estar que nos signa en nuestro habitar americano" (Bosio y Haddad, 2015, p. 132), en el que ha profundizado Rodolfo Kusch como ningún otro pensador.

Según Bordas, el estar ofrece algunas relaciones con el ser: si dicha relación es integradora, la relación puede ir del ser al estar (como es el caso de Heidegger y parte de la filosofía europea), o puede ir del estar al ser (como es el caso de Kusch y una línea de la filosofía latinoamericana). Sin embargo, si la relación es contradictoria, puede darse un distanciamiento del estar, como pasa con el ser occidental moderno o el impuesto en América; o un distanciamiento del ser, como en el pensamiento popular latinoamericano (Bordas, 1997, p. 61).

En efecto, en Kusch el estar siendo va del estar al ser, pero dentro de un esquema de circularidad mandálica, como le gustaba sugerirlo: están los objetos en el "patio de los objetos", que la pequeña historia del ser ha ido acumulando hasta perderse el sentido (todo sentido). Para recuperarlo, deben negar-se esos objetos y, así, encontrar-nos con la vida, ir hasta sus raíces, y poder "arrancar" de lo más profundo su sentido seminal. Esta es la forma en que nos devolvemos a la vitalidad del estar; solo ubicados en este nivel podremos dirigirnos, renovados, al ser, para preguntar por su sentido. Además, esto posibilitará, seguramente, una respuesta a tan insistente interrogante; aunque ahora la misma pregunta — si nos mantenemos atentos— no dejará que "caigamos" en la objetividad racional, como al inicio, sino que se dará en un plano que abrirá la opción a una comprensión más íntegra de lo preguntado. 
Podríamos decir que en este mandala ontológico se sintetiza la apuesta filosófica de Rodolfo Kusch. Y como mandala, parte del misterio se nos muestra y otra parte queda velada. Este mismo mandala que se nos impone en la investigación que acá desarrollamos solo se mostró en parte en las indagaciones de Kusch. Él mismo no fue por completo consciente de esta circularidad con que, de forma mágica, se nos presenta ahora su obra.

Por demás, es la última conclusión que podemos avizorar al finalizar esta larga etapa del proyecto de investigación que, en verdad, inició hace catorce años, en 2002. Ahora bien, desde el corazón de lo alcanzado hasta este momento emergen con asombro nuevas preguntas, nuevas posibilidades de investigación, propias — de todas formas- de esa riqueza, como infinita, que mana de las obras de este gran filósofo latinoamericano.

Sin embargo, deben ahora mismo aclararse algunos de los límites que se le imponen a este estudio. No debe perderse de vista que "a lo largo de su investigación Kusch mantiene sin atenuantes la afirmación de la prioridad ontológica del estar sobre el ser y la necesidad de una coherencia entre ambos" (Bordas, 1997, p. 56). Dicha coherencia entre ambos, como ya se explicitó, pone al ser bajo el horizonte del estar, y por ello Bordas habla de "prioridad". Con ello se evita recaer de nuevo en la polarización —sea del ser o sea del estar-, porque lo que se ha ganado es un equilibrio ontológico que debemos esforzarnos en mantener, acorde con la misma realidad.

Desde ya se prevé que, de lado y lado, en los extremos, lloverán críticas y rechazos, puede que bien argumentados. Al fin y al cabo todo mandala es la expresión de un pensar simbólico; es decir, la expresión de un ser humano situado geoculturalmente, y esto, de antemano, no puede ser comprendido por tradiciones científicas o filosóficas que se han esforzado en evidenciar la objetividad racional del conocimiento del mundo. Un proyecto de comprensión de sentido del ser, bajo el horizonte de la propuesta filosófica como la acá expuesta "ha sido aislado y evitado siempre por las autoridades académicas y canónicas" (Pérez, 2013, p. 111).

Entonces, no queda más que acogernos a los lineamientos del mismo Kusch cuando decide indagar en lo profundo de América, en las 
raíces del pensamiento indígena y popular latinoamericano, en búsqueda no de una verdad meramente objetiva y racional, sino de la verdad íntegra, aquella que sí ha de posibilitarnos un sentido, el sentido existencial de lo que somos, desde cómo estamos. Vale recordar que Rodolfo Kusch no rechaza la objetividad, la racionalidad o la ciencia y su tecnología, pero sí les niega el valor absoluto que Occidente les ha concedido, y no podría ser de otra manera, porque, como es evidente, todo ello no es más que una parte de la verdad, y - como dice Kusch- una parte muy pequeña.

Las emociones, los sentimientos y las opiniones también nos conducen a la verdad, y hacen parte de la verdad íntegra. De igual manera, la cultura no hará parte de la verdad objetiva, pero sin ella no hay verdad. Y no se trata solo del contexto cultural en que se da la verdad, se trata de que la única manera en que se da esta es como saber cultural. O por lo menos entre los seres humanos no puede ser de otra manera. Y esto se hace complejo cuando evidenciamos la pluralidad de culturas en que nos movemos, en que estamos siendo. Aún más: no se limita a la multiculturalidad, pues también existe la interculturalidad y la transculturalidad. De acá la importancia fundamental de la filosofía intercultural a la hora de comprender una propuesta como la de Kusch: ella diluye los prejuicios ratiocéntricos de la llamada filosofía universal y nos abre los oídos y el olfato para ofrecer el debido puesto a la otredad; es decir, a otras formas de la filosofía que no tienen por qué amoldarse a los principios, a las categorías, y a los métodos que una sola cultura quiere imponer.

"Manteniéndonos en nuestro tema del estar, Kusch parece considerar que este genera cierta forma de pensar y cierta forma de valorar. Estar y ser indicarían dimensiones de la existencia humana que serían desigualmente experimentados y vividos según las diversas culturas" (Sada, 1996, pp. 126-127). Sin embargo, la filosofía, como tarea del pensar que busca la verdad del modo más ajustado posible, podría acertar en lograr el equilibrio entre estas manifestaciones de lo-que-es-y-está, llevando a una armonía en la comprensión de lo que somos y de lo que es: el ser.

De lograr el alcance de semejante reto, también estaríamos esbozando el diseño de una cosmología que daría cuenta de objetos y leyes 
propias de la física matemática, pero además, de ciertas manifestaciones emocionales cósmicas, como las señaladas por el pensamiento indígena (el miedo, la "subjetividad" de lo “objetivo", el amor ecológico, entre tantas otras), así como también de lo sagrado. En este sentido, debe anotarse que, en efecto, la ontología de Kusch apunta a una cosmología, rica y profunda, que iría mucho más allá de las apuestas teóricas, mágicas o científicas, que han ido construyéndose, cada una por su lado, y que el mismo Kusch no desarrolla, puesto que ese no es su interés.

Para finalizar, parece necesario también decir algo con respecto a Heidegger, a propósito de la primera parte de esta investigación. Ya lo expresó de manera precisa Sada: Kusch "presenta claramente las huellas heideggerianas pero no es un expositor de Heidegger" (1996, p. 212), como, por demás, se ha comprobado en este documento. El interés ontológico de Heidegger, en efecto, se imprime en Kusch, pero en el filósofo alemán es central y podría decirse que "único", mientras que en el filósofo argentino es "primordial”, porque está en la base de todas sus investigaciones y las nutre, pero funge solo como un propósito tangencial.

Heidegger "no es alguien que aquí más o menos lo ha repetido agregándole algunas críticas o suplementos propios, sino que el pensador alemán queda transmutado en otra problemática" (Sada, 1996, p. 212). Ni Kusch lo repite ni - tampoco- lo discute de manera frontal, digamos, de forma dialéctica. Más bien lo asume de modo crítico para avanzar en el cometido que se ha propuesto, lo entiende a la luz del estar, lo lee desde el contexto cultural latinoamericano, y lo asume, con cierta indiferencia, cuando trata asuntos que no considera esenciales. De todas maneras, la ontología, desde el siglo xx, pasa, de forma obligada, por la comprensión que de ella hiciera Martin Heidegger, y su exposición ha sido fundamental y enriquecedora para ofrecer el marco teórico de la presente investigación.

¿Qué resta por decir? Por decir, de seguro, nada.

Nada más hay que decir.

En cambio, sí hay mucho qué callar.

Hacer silencio.

Meditar. 
Saberse estando

y estando, hundirse en el ser,

hasta las raíces

donde hiede la vida,

donde oscurece la razón,

donde se siente el corazón

y se vive en alegría

de saberse estando

mientras se está callando

lo que no se dice.

Hieden, ya, tantas palabras.

Hieden los argumentos.

Como hieden los monumentos

a los héroes de la razón

que vivieron sin pasión

todo lo que escribían...

¡Es mejor la sabiduría

indígena y popular

que nos lleva a vivenciar, con sentido profundo,

por qué estamos en el mundo

y por qué es mejor, ya, callar! 